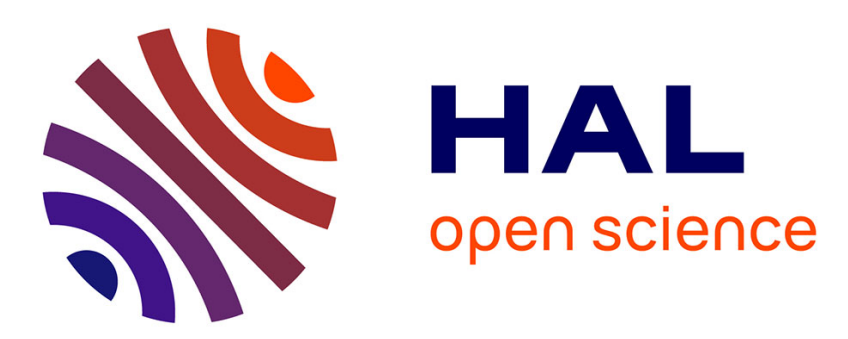

\title{
A STUDY ON THE FORMATION MECHANISMS OF THE CUBE RECRYSTALLIZATION TEXTURE IN COLD ROLLED Fe-36\%NI ALLOYS
}

S Zaefferer, T Baudin, R Penelle

\section{- To cite this version:}

S Zaefferer, T Baudin, R Penelle. A STUDY ON THE FORMATION MECHANISMS OF THE CUBE RECRYSTALLIZATION TEXTURE IN COLD ROLLED Fe-36\%NI ALLOYS. Acta Materialia, 2001. hal-03300294

\section{HAL Id: hal-03300294 \\ https://hal.science/hal-03300294}

Submitted on 3 Aug 2021

HAL is a multi-disciplinary open access archive for the deposit and dissemination of scientific research documents, whether they are published or not. The documents may come from teaching and research institutions in France or abroad, or from public or private research centers.
L'archive ouverte pluridisciplinaire $\mathbf{H A L}$, est destinée au dépôt et à la diffusion de documents scientifiques de niveau recherche, publiés ou non, émanant des établissements d'enseignement et de recherche français ou étrangers, des laboratoires publics ou privés. 


\title{
A STUDY ON THE FORMATION MECHANISMS OF THE CUBE RECRYSTALLIZATION TEXTURE IN COLD ROLLED Fe-36\%NI ALLOYS
}

\author{
S. ZAEFFERER $\dagger$, T. BAUDIN and R. PENELLE
}

Université de Paris-Sud, URA CNRS 1107, 91405 Orsay Cedex, France

\begin{abstract}
The formation of sharp cube recrystallization texture after high cold rolling reductions in $\mathrm{Fe}-$ $36 \% \mathrm{Ni}$ has been studied by means of X-ray texture measurements and extensive transmission electron microscopy (TEM) observations, including orientation measurements even in highly deformed materials. In contrast to $\mathrm{Cu}$ and $\mathrm{Al}$, this material shows only little recovery during cold deformation; therefore, the deformation structure can be studied in detail. After high cold rolling the cube grains present at the hot rolled state show the formation of cells and the development of a large orientation gradient inside cube bands. During recrystallization nucleation of cube grains proceeds at a high rate inside these structures. For low deformations cube grain nucleation seems to be inhibited due to the insufficient orientation gradient across the cells. Regions of other orientations show a much lower nucleation rate owing to their inappropriate microstructure. Thus, other recrystallization textures only develop if the cube nucleation is inhibited.
\end{abstract}

Keywords: Transmission electron microscopy (TEM); Steels-austenite; Microstructure; Texture; Recrystallization \& recovery

$\dagger$ To whom all correspondence should be addressed at: Max-Planck-Institute for Iron Research, MaxPlanck-Str. 1, 40237 Du“ sseldorf, Germany

E-mail address: zaefferer@mpie.de (S. Zaefferer) 


\section{INTRODUCTION}

The sharp cube texture which appears during recrystallization of cold rolled fcc materials with high stacking fault energy has been the subject of intense research for 60 years. Although the effects are strikingly clear, questions remain and research in this area is continuing.

The transformation in texture from the copper-type cold rolling texture to the sharp cube texture has attracted attention because the $\mathrm{Fe}-36 \% \mathrm{Ni}$ alloys with this cube texture are used for electrical engineering applications where magnetic transformer cores are produced from stacked laminations. In this case a sharp cube texture is highly welcome because it reduces magnetic losses. Another important application is that of shadow masks placed immediately behind the screen in color television tubes. Here the cube texture is only the second best with respect to a precise etching of the mask. Besides industrial interest, formation of the cube texture is also of interest as a model case to test the hypotheses of oriented growth and oriented nucleation as mechanisms of recrystallization texture formation. Both theses have been defended over a long time by different research groups (see [1-3] for an overview) but a survey of the recent literature on the formation of the cube recrystallization texture in $\mathrm{Al}$ and $\mathrm{Cu}$ (for example [4-7]) reveals a strong tendency to favor a mechanism of oriented nucleation from cube oriented regions in the deformed matrix. It should, however, be mentioned that the theory of oriented growth has gained some support by the recent idea of orientation pinning $[8,9]$.

Nevertheless, for the theory of oriented nucleation it is not yet completely clear (i) where the cube oriented regions in the deformation structure come from and (ii) how a vital nucleus develops from these regions. For point (i) two mechanisms have been proposed. One is the retention of cube oriented regions from originally cube oriented grains in the starting structure [10, 11]. This mechanism is based on the observation that cube grains are rather stable against crystal rotations during cold rolling. The second mechanism assumes the rotation of non-cube oriented material towards this orientation. Different rotation mechanisms have been proposed [12, 13] and proved experimentally $[14,15]$ and by simulations [16].
Point (ii) has been put into question by two facts: first, $\mathrm{Cu}$ and $\mathrm{Al}$ and many of their alloys recover quite easily at room temperature but even more at elevated temperatures which occur shortly during cold rolling. Thus, what is seen in these "deformed" microstructures after cold rolling is often a strongly recovered or even partially recrystallized microstructure where the process of nucleation has already been terminated. If, however, a material does not recover easily and allows observation of the real deformed structure the problem of measuring orientations in these structures arises. The EBSP technique which has been applied in most of the recent studies does not allow the measurement of orientations in these structures. In order to avoid these difficulties sometimes a "slight anneal" is carried out which, in turn, destroyed the deformation structure. But even with transmission electron microscopy (TEM), where the sensitivity to sample deformation is less owing to the increased spatial resolution, the problems of measuring orientations in highly deformed structures are serious.

In the current work both problems have been overcome by using the fcc alloy $\mathrm{Fe}-36 \% \mathrm{Ni}$ which has a high stacking fault energy. $\dagger$ It shows a deformation and recrystallization texture behavior very similar to that of $\mathrm{Al}$ or $\mathrm{Cu}$ but recovers only very little during cold rolling owing to its higher melting point and to the high concentration of two elements. For the difficult measurement of orientations in these microstructures a special computer program for the on-line orientation determination in TEM was developed [18, 19]. In this way the deformation structure can be observed and orientations can be measured up to the highest degree of deformation $(95 \%)$.

Extensive local orientation measurements using TEM and global texture X-ray measurements provide some insight into how cube oriented regions develop during deformation, their properties and how nuclei and subsequently new grains develop from these regions during recrystallization. It should be borne in mind, however, that other materials $(\mathrm{Cu}$ and $\mathrm{Al})$ might show different mechanisms to those observed in this study. 


\section{EXPERIMENTAL TECHNIQUES}

Hot rolled material with a very fine grain size of about $10 \mu \mathrm{m}$ was cold rolled to deformations of 20 , $40,64,73,79,85$ and $94 \%$. Recrystallization experiments were carried out on the samples deformed 64$94 \%$. The samples were placed in a preheated furnace and annealed at $600^{\circ} \mathrm{C}$ under primary vacuum for the short time experiments ( 1 and $2 \mathrm{~min}$ ) and under $\mathrm{H}_{2}$ atmosphere for the longer annealing times. The global texture was measured on all samples using X-ray diffraction. The microstructure and the local orientation distributions were observed by TEM on deformed samples as well as on 1- and 2-min annealed samples. The kinetics of recrystallization were determined by micro-hardness measurements.

The global texture measurements were carried out on the ND-TD plane in order to average over the texture gradient from the rolling surface to the center of the material. The textures were evaluated using the component method of Helming [20] which allows the determination of Gauss type texture components by an interactive search and fit algorithm.

TEM samples were prepared either from the NDTD (transverse section) or from the ND-RD (longitudinal section) plane. Samples showing a high degree of deformation were electroplated with pure $\mathrm{Ni}$ in order to increase the thickness of the sheets. From the Ni-plated sandwiches slices were cut and mechanically and electrolytically polished [21]. The samples used for the short time recrystallization experiments were Ni-plated prior to the heat treatment.

The observation of the samples was carried out on a Jeol 2000 EX TEM equipped with a system for the on-line measurement of local orientations from Kikuchi and spot diffraction patterns [18, 19]. Since the alloy $\mathrm{Fe}-36 \% \mathrm{Ni}$ recovers only little during cold rolling, a high dislocation density is created during deformation. Together with the minimum beam size of 30-50 nm which can be achieved with the microscope used, no or only very blurred Kikuchi patterns are obtained in the most highly deformed material which is, however, the most interesting one for the recrystallization studies. In this case micro beam spot diffraction patterns were used. The on-line measurement system allows the orientation determination from spot patterns with almost the same precision as for Kikuchi patterns owing to the automatic evaluation of spot intensities.
The measured orientations are represented in orientation maps [22]. These maps are created in the following way. For each cell or sub-grain one orientation measurement is carried out. The grain structure of the material is digitized and colored according to the orientation of the cells. The color is chosen by overlapping a standard orientation triangle with a color triangle. In this way each crystal direction is unequivocally related to a color. Since a crystal orientation is fixed by two crystal directions (usually the crystal directions parallel to ND and RD) each orientation is represented by two colors, one for the normal direction and one for the rolling direction. The microstructures are therefore shown twice: the colors in the first image correspond to ND, the ones in the second correspond to RD. 


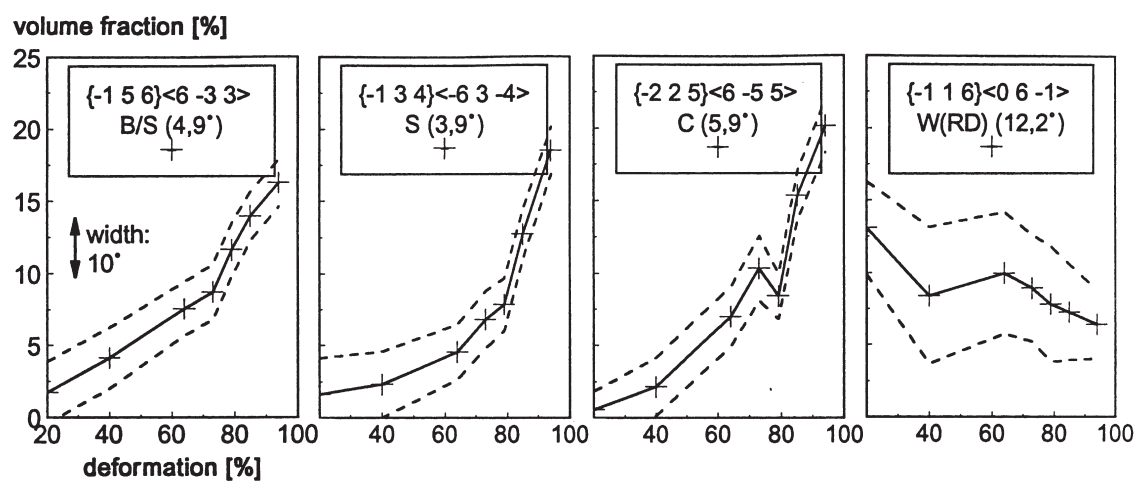

Fig. 1. Development of the volume fraction and the width of the most important texture components during cold rolling. Solid lines show the volume fraction as indicated on the $y$-axis. The broken lines show the width (FWHM) of each component as indicated by the arrow in the figure at the bottom left. The approximate component positions in $(h k l)<u v w\rangle$ and the distances (in degrees) of the component to the closest ideal compo-nents are indicated.

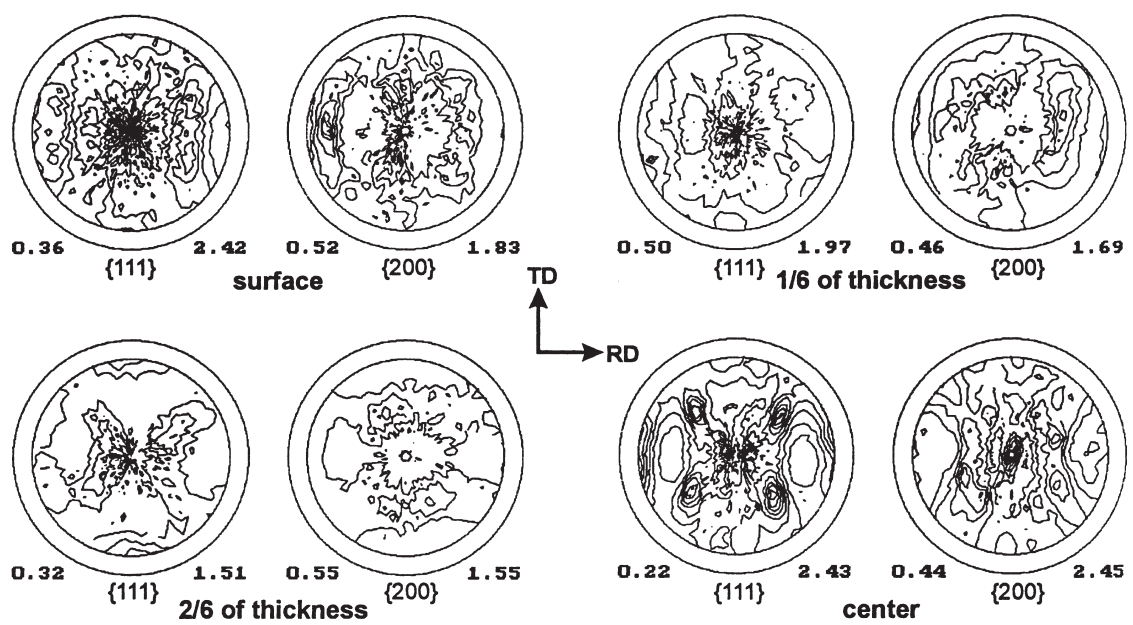

Fig. 2. $\{111\}$ and $\{200\}$ X-ray pole figures from the normal plane of the hot rolled material measured on the surface and at different depths below it. Contour levels are given in steps of 0.25 from the maximum (dark line) to the minimum (bright line). Maximum and minimum values are given on the left and right sides, respectively. 


\subsection{The texture and microstructure of the deformed state}

3.1.1. Texture. The cold rolling texture evolution has been determined by observing the width and volume fraction of 11 characteristic texture components as a function of the degree of deformation. Figure 1 shows the evolution of volume fraction and width of the four most important components. The components are denoted by their closest ideal component together with the appropriate orientation distance to this component. $\dagger$ Two different regions can be distinguished. For deformations lower than $75 \%$ a rather slow development of most of the components is observed. Components close to the $\mathrm{B}$ component are slightly decreasing while components close to $\mathrm{C}$ and

$\mathrm{S}$ are slightly increasing. The second region, for deformations higher than $75 \%$, is characterized by the strong increase and sharpening of the $\mathrm{S}$ and $\mathrm{C}$ components and a decrease of those components close to the B component.

Of great importance for this work is the behavior of the cube component. The cube component already present in the hot rolled material decreases slowly during rolling. Even after the highest rolling reductions a non-negligible volume fraction is present. The texture of the hot rolled material is rather different across the sample thickness. Pole figures from the surface and the center of the material are shown in Fig. 2. At the surface the material shows a weak brass texture tilted towards the rolling direction and at the center a slight cube texture.

3.1.2. Microstructure. Special attention has been paid to the evolution of the deformation structure in cube or near-cube oriented grains ("cube grains") and their differences to non-cube oriented grains. The first such differences become evident after $40 \%$ of deformation. In cube grains dislocation cells begin to form, visible on the ND-TD plane (Fig. 3b). The cell boundaries become sharper with increasing deformation. After low deformations the cells are a couple hundred nanometers in size and are $2-5^{\circ}$ misoriented with respect to their neighbors. The cell interior contains few dislocations. The non-cube grains, in contrast, develop widely spaced dense dislocation walls (DDW) (Fig. 3a). The distance between the DDW decreases with increasing deformation from $1 \mu \mathrm{m}$ after $40 \%$ to about $50-100 \mathrm{~nm}$ after $94 \%$ of deformation (Fig. 6).
From about $60 \%$ deformation the formation of a continuous orientation gradient in the transverse direction in cube grains is observed. Its development starts at a grain boundary or a triple point and, in the case of low deformations, covers only a small region of the grain. Figure 4 shows an orientation map of a cube grain after $73 \%$ deformation. The white parts close to triple points correspond to these continuously misoriented regions and show a complicated arrangement of cells. The misorientations between the cells (solid points) and across the whole region (solid line) measured in the scan parallel to the arrow are presented in the corresponding graph. The misorientations between the cells vary between 2 and $4^{\circ}$, whereas the misorientation across the band accumulates to about $15^{\circ}$. The cell orientations are shown in $\{111\}$ and $\{200\}$ pole figures. It can be seen that the rotation axis for the cells in the line scan (shown by the circles in the pole figures) is close to the rolling direction, which itself is parallel to $\langle 100\rangle$. With increasing deformation the region covered by the homogeneous cell rotation grows into the grain. From cell to cell the cube orientation $\{100\}<001>$ is successively rotated around the rolling direction towards an orientation $\{210\}<001>$. Because these deformed cube grains are rather flat and elongated in the rolling direction they are called cube bands (CB) like similar structures in $\mathrm{Al}$ and $\mathrm{Cu}[7,11,24]$. These bands must not be confused with transition bands in the sense of Dillamore $[12,25]$ or others $[13,16]$ which show a homogeneous orientation transition between two stable rolling texture components.

$\dagger$ The components are nominated according to Hirsch and Lu"cke [23]: Brass or "B" for $\{011\}<211>$, "B/S" for $\{146\}<211>$, "S" for $\{123\}<634>$, "C/S" for $\{348\}<322>$ and Copper or "C" for $\{112\}<111>$, Goss or "G" for $\{011\}<100>$, Cube or "W" for $\{001\}<100>$. The cube component rotated around the rolling direction is nominated "W(RD)" and $\{210\}<001>$ which is situated half way between W and G is called WG. 


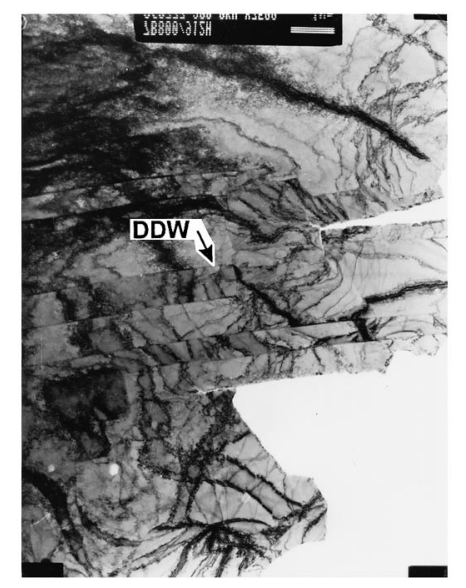

a)
$2 \mu \mathrm{m}$

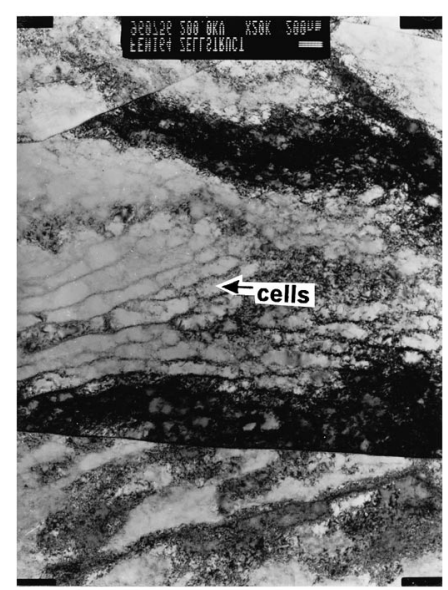

b)

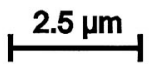

Fig. 3. TEM micrographs showing the beginning of diversification of cube and non-cube grains after low deformations. (a) Dense dislocation walls (DDW, indicated in the figure) in a non-cube grain $40 \%$ deformed by cold rolling. (b) Dislocation cells (indicated in the figure) in a cube grain $64 \%$ deformed by cold rolling.
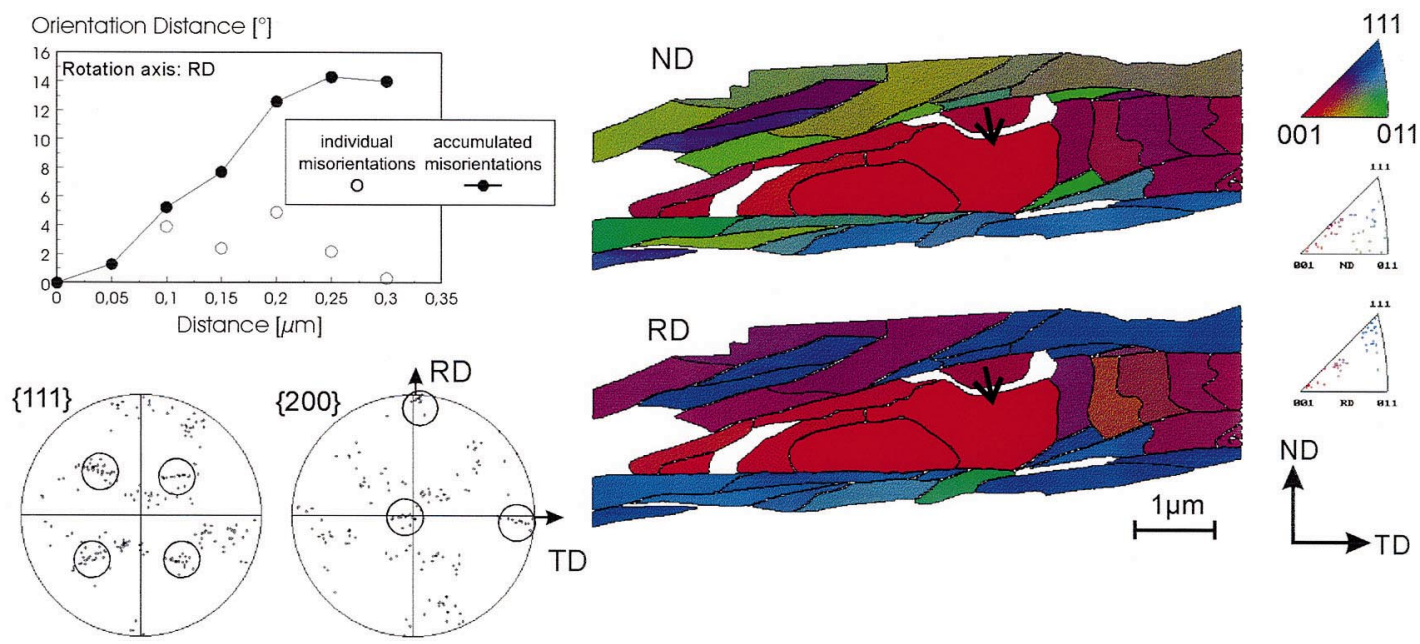

Fig. 4. Orientation map of a cube grain and its surroundings in $73 \%$ deformed material measured in the TEM on the ND-TD plane. The graph on the left side indicates the misorientation measured along the black arrow in the map. The appropriate orientations are marked by circles in the single orientation pole figures. See text for details. 


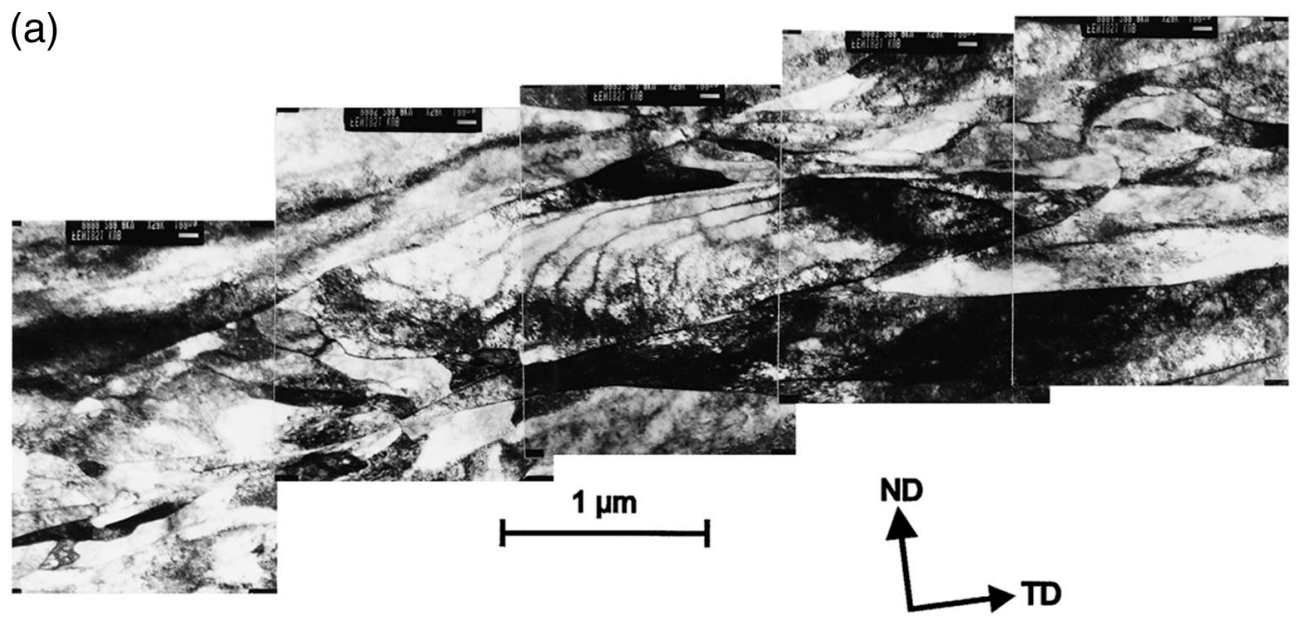

(b)

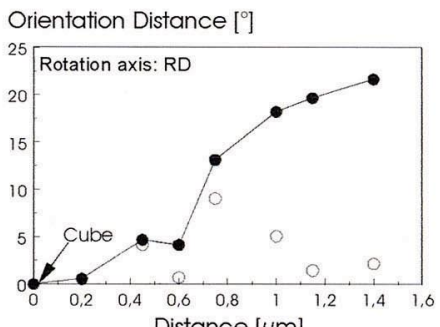
Distance $[\mu \mathrm{m}]$

individual accumulated $\underset{0}{\operatorname{misorientations}} \underset{0}{\mathrm{misorientation}}$

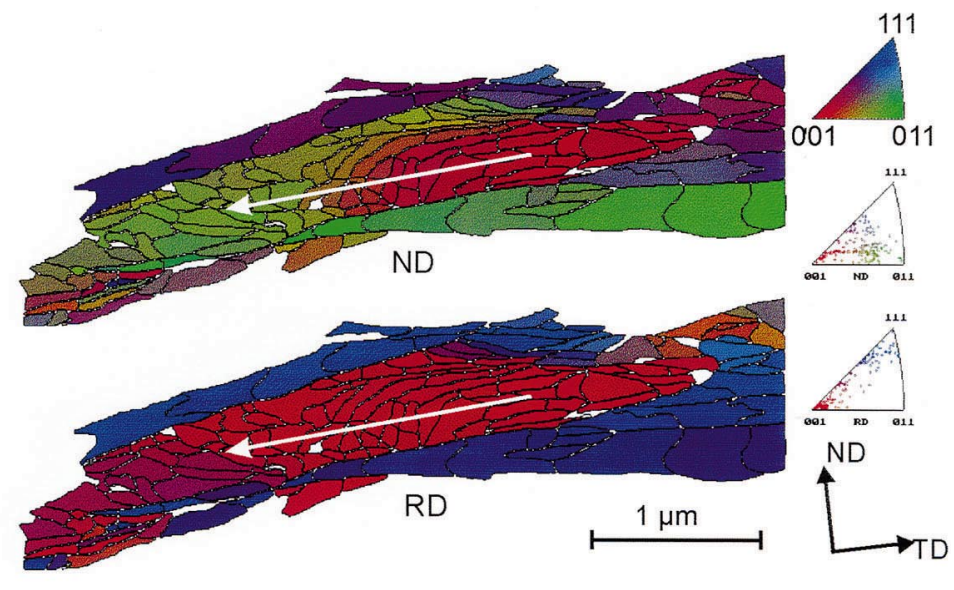

Fig. 5. (a) TEM micrograph and (b) orientation map from a cube band in the $85 \%$ deformed material measured on the ND-TD plane. The graph on the left side indicates the misorientations measured along the white arrow in the map. 
(a)

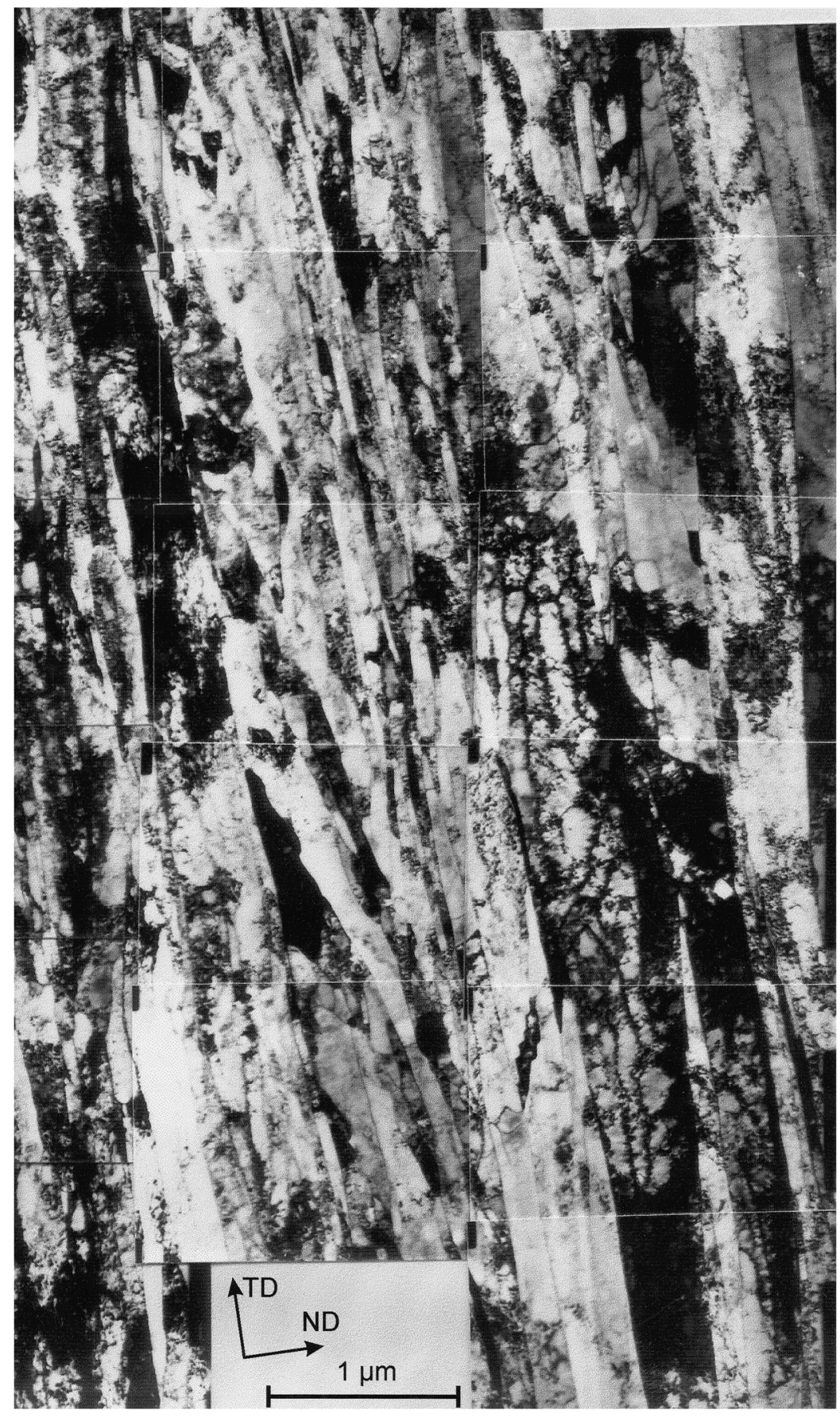



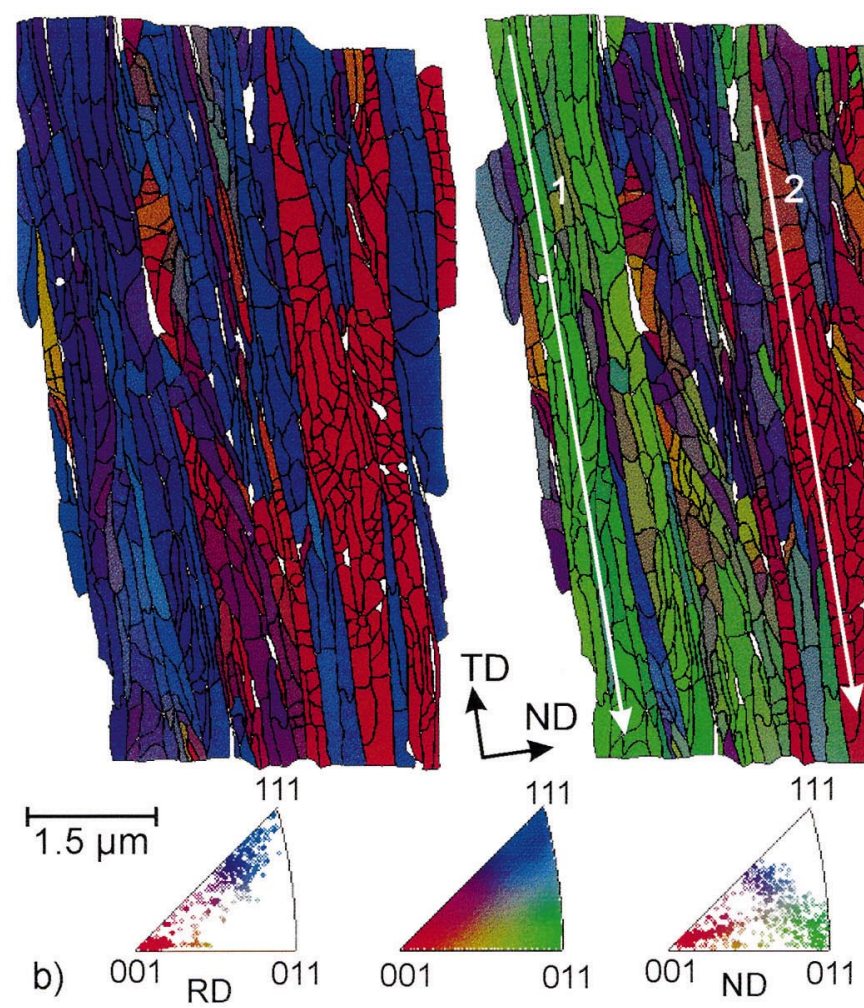

111

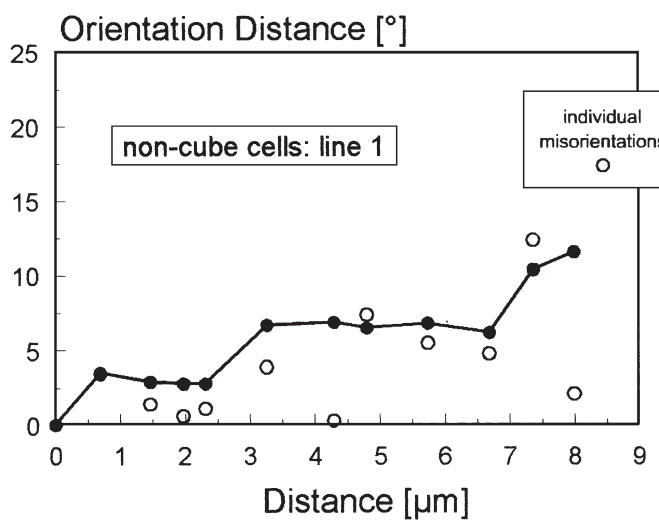

d)
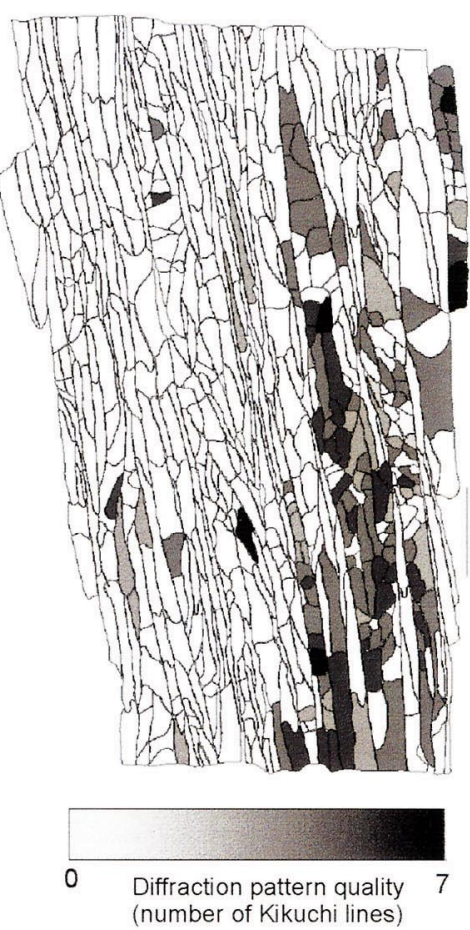

C)

Orientation Distance $\left[{ }^{\circ}\right]$
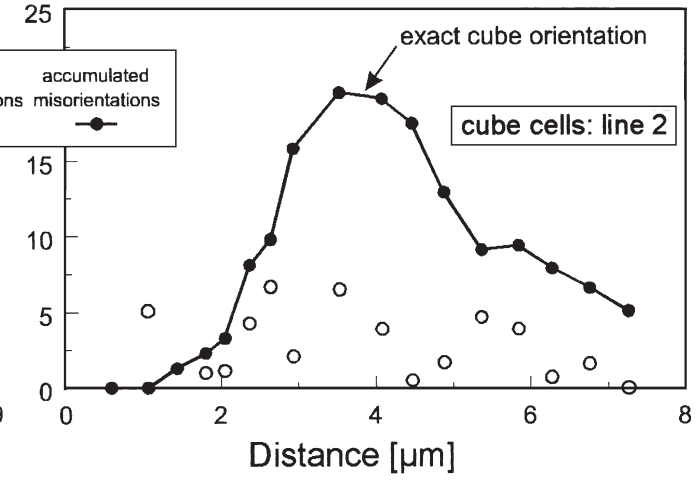

e)

Fig. 6. (a) TEM micrograph, (b) orientation map and (c) pattern quality map from lamella bands and a cube band in the $94 \%$ deformed material (ND-TD plane). (d) Misorientations measured in the lamella bands (in direction of white arrow no. 1 in the upper orientation map). (e) Misorientations measured in the cube band (arrow no. 2). 
After high deformations well developed orientation gradients in the transverse direction are observed in all grains with an orientation close to the cube orientation. The area-density of these structures has been measured to $7.1 \times 10^{9} \mathrm{CB} \mathrm{m}^{-2}$. In most cases the misorientations across these bands exceed $25^{\circ}$ with a rotation axis close to the rolling direction. Figure 5 shows a band in an $85 \%$ deformed material. The cube oriented cells lie on one side of the grain and the orientation gradient extends over the whole grain. It has been shown by the quality of Kikuchi diffraction patterns that the cube oriented cells are frequently those with the lowest density of dislocations. The number of Kikuchi bands easily recognizable by the user has been used as a measure of the pattern quality. This measure is not a quantitative one but reflects the general trend quite clearly. In Fig. $6 \mathrm{c}$ the grains in the microstructure shown in Fig. 6a are shaded according to their respective pattern quality. The grains close to the cube orientation (Fig. 6b) show the highest quality and thus contain the lowest density of dislocations. In contrast, the lamellar bands (LB) show a very low pattern quality, hinting at a very high internal dislocation density. The misorientations along or across these band structures are heterogeneous and no significant misorientation is accumulated (Fig. 6d).

In the RD-ND plane the $\mathrm{CB}$ appear as elongated cell structures with a length of more than $10 \mu \mathrm{m}$ and a thickness (size in ND) of 100-200 nm (Fig. 7). The cells in cube bands thus have the form of tubes with an elliptic section. No significant orientation gradient was found along the band in the rolling direction.

In some non-cube grains shear bands have been observed from $85 \%$ deformation on the RD-ND plane. They are only found in grains of the $\mathrm{C}$ $(\{112\}<111>)$ matrix orientation and are always restricted to only one original grain. Figure 8 shows two shear bands in the $94 \%$ deformed material and their respective orientations (Fig. 8b). Small white areas in this map correspond to areas which could not be measured, not even with spot patterns, owing to the high localized deformation. Cells directly inside the shear band show a significant orientation change. The misorientations between some of these cells and the matrix cells correspond to a twin relation $\left(60^{\circ}\right.$ $<111>$ ).

\subsection{The recrystallization texture and microstructure}

In order to facilitate reading the different samples will be named as follows. The first unity starts with "c" for cold rolling followed by the degree of deformation in \%. The second unity starts with " $\mathrm{r}$ " for recrystallization followed by the recrystallization time in seconds or by "CMP" for complete recrystallization. A sample named c94rCMP thus indicates a $94 \%$ deformed and subsequently completely recrystallized sample.
3.2.1. Kinetics and texture. The kinetics is presented in Fig. 9 as recrystallized volume fractions calculated from the hardness measurements. The curves indicate that the most highly deformed sample (c94) begins to recrystallize significantly earlier (after $5 \mathrm{~min}$ ) than the other samples (after about $10 \mathrm{~min}$ ). For the most highly deformed samples (c94 and c85) recrystallization is terminated after about $1 \mathrm{~h}$. The others are completely recrystallized after about $2 \mathrm{~h}$.

Evolution of the recrystallization texture as a function of deformation degree prior to recrystallization is shown in Fig. 10a by means of the volume fraction and width of three characteristic texture components. The component $\mathrm{B} / \mathrm{S}$ is well developed in the material c64rCMP. It should be noted that this component exhibits a rather large width and thus comprises many different orientations. With an increasing degree of deformation this component decreases strongly and disappears for samples $c \geq 90 \mathrm{rCMP}$. For $\mathrm{c} \geq 80 \mathrm{rCMP}$ the cube component starts to develop strongly. In the sample c94rCMP the cube texture is completely developed. It consists of $70 \%$ volume fraction of cube grains and $10 \%$ of cube twins.

The development of the texture as a function of recrystallization time is shown in Fig. 10b for $94 \%$ deformation and in Fig. 10c for $79 \%$ deformation. Each graph displays the evolution of volume fraction and width of four characteristic texture components. The material c94 shows a first slight increase of the cube component between 2 and 5 min. The strong onset of cube recrystallization is observed after $5 \mathrm{~min}$. The deformation components $\mathrm{B}, \mathrm{B} / \mathrm{S}, \mathrm{C}$ and $\mathrm{S}$ all show a very similar behavior (only B is shown in Fig. $10 \mathrm{~b})$. They are consumed by the growing cube grains at about the same rate. A preferred consumption of any of the deformation components is not observed. It is important to note the existence of a component $\{411\}<235>$ in the far $\mathrm{S}$ environment which starts to grow and then disappears again. The calculated volume fraction of this peak might be too high due to a slight overlap with the twin component. However, some grains of this orientation were also found by EBSP measurements on partially recrystallized material. The material c79 (Fig. 10c) shows, at about $10 \mathrm{~min}$, a significantly longer incubation time than c94 (5 min). However, it is even more important to note that this material shows a distinctive difference in the growth kinetics of different texture components. After $10 \mathrm{~min}$ the growth of the cube component can be observed. The strong onset of recrystallization, however, is observed only after $30 \mathrm{~min}$, when the B/S component starts to develop. It should be noted that the width of this component is rather large and thus many different orientations are comprised within this peak. 
3.2.2. Microstructure after short time annealing of the 94\% deformed material. For TEM, 1- and 2min annealed samples were chosen. Special attention was paid to the evolution of the cube bands. After 1 min of annealing the $\mathrm{CB}$ are easier to observe than in the deformed microstructure because the contrast between cell boundaries and cell interior is more pronounced (Fig. 11a). The cell boundaries are wider and less sharp. The appropriate orientation map in Fig. $11 \mathrm{~b}$, in contrast, shows no change compared with the deformed material but it was frequently observed that the diffraction pattern quality decreased compared with the deformed material. This might indicate the increase in dislocation density in the sampled volume. In grains of non-cube orientation no significant structure change was observed.

After 2 min of annealing the nucleation stage was reached. Figure 12 shows a typical microstructure (a) and the appropriate orientation map (b). The cube ori-

ented region in the middle already contains a large recrystallized region of more than $1 \mu \mathrm{m}$ diameter which develops inside the former cube band. Some of the former cell boundaries in the band are still visible. The growth of the recrystallized region seems to proceed mainly inside the band although some bulging into the deformed matrix is also visible. The misorientations between this band and its neighbors in the matrix are shown in Table 1. At this stage recrystallized grains up to a diameter of about $2 \mu \mathrm{m}$ are found. All observed nuclei show orientations comprised in the CB orientations between $\mathrm{W}$ and WG. In contrast, in non-cube oriented regions the increase in the quality of diffraction patterns indicates only the recovery or polygonization of dislocations. Nucleation is not observed. 

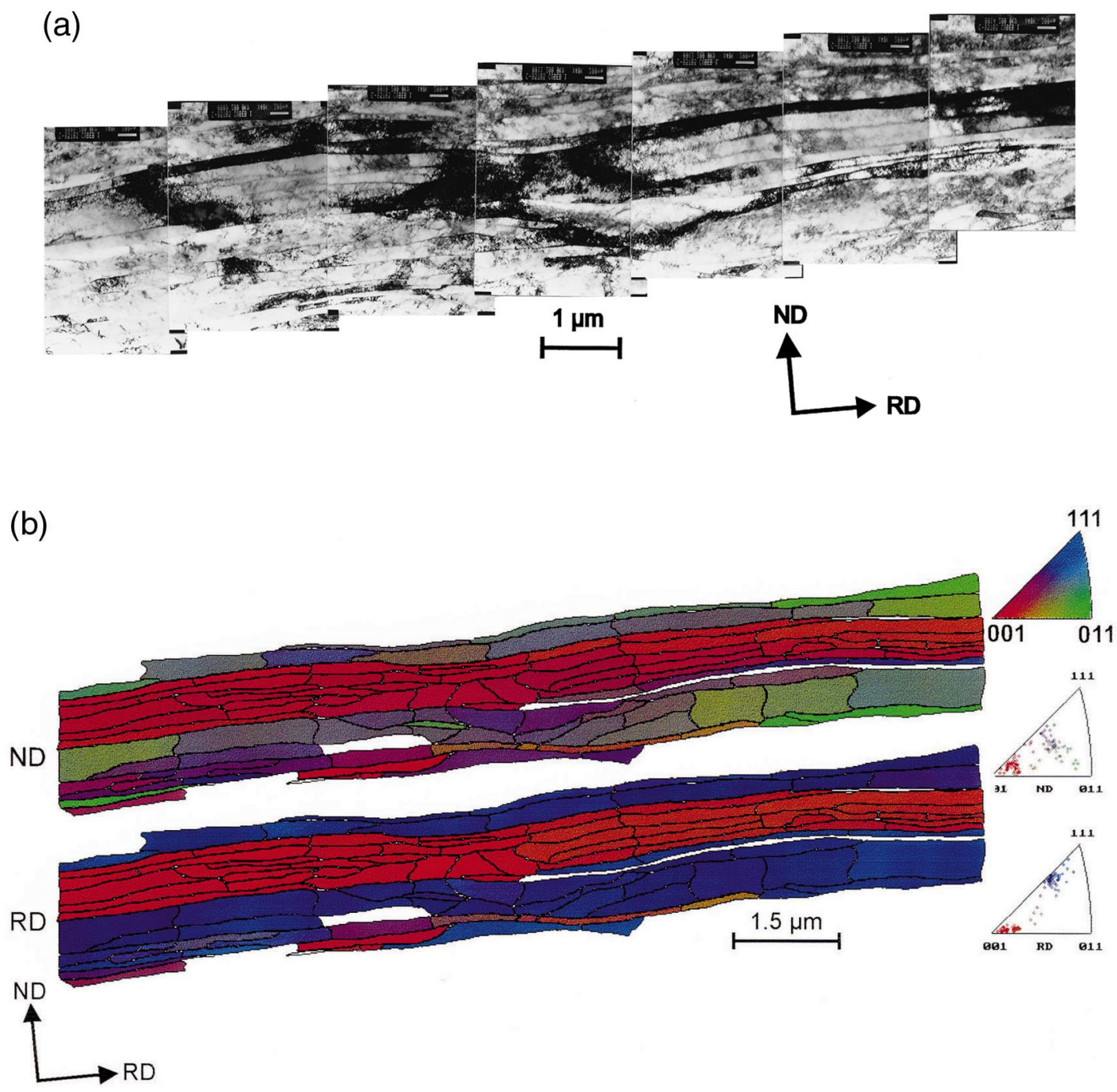

Fig. 7. (a) TEM micrograph and (b) orientation map of a cube band and lamella bands in the $94 \%$ deformed material measured on the longitudinal section (ND-RD plane). 
(a)

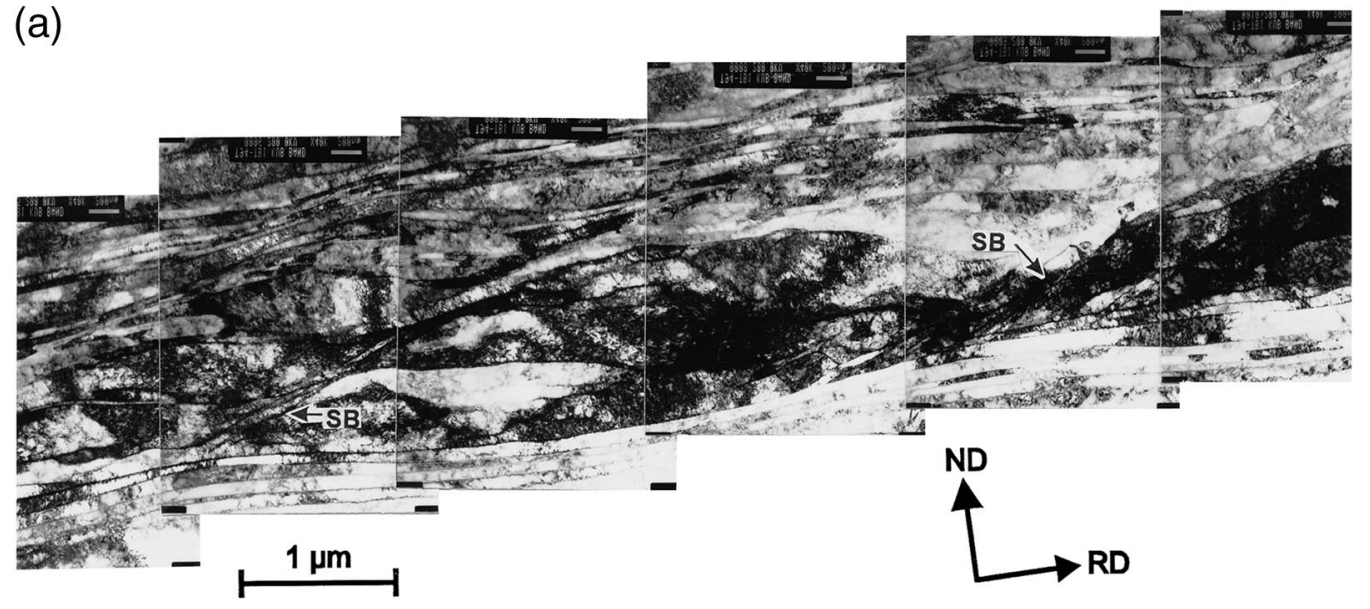

(b)

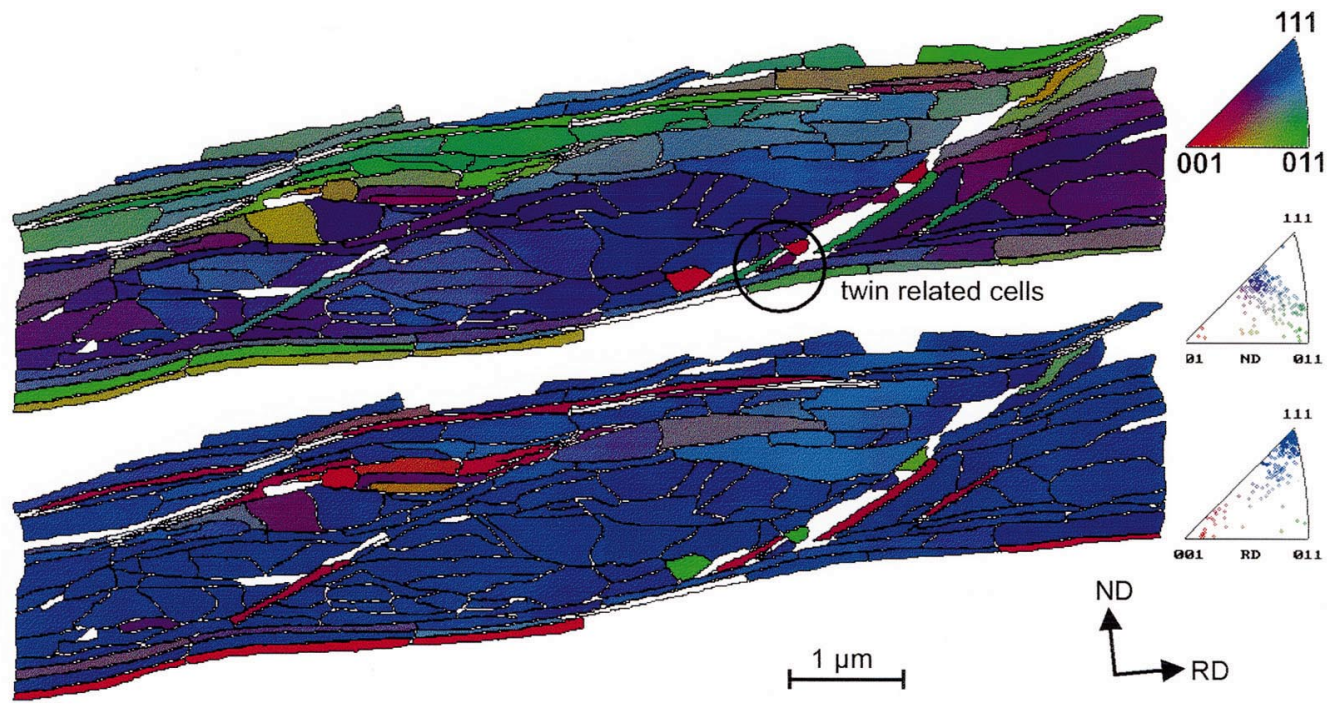

Fig. 8. (a) TEM micrograph and (b) orientation map of a shear band (SB, indicated in (a) in the $94 \%$ deformed material (ND-RD plane). The black circle indicates subgrains which show a twin orientation relation with the surrounding matrix subgrains.

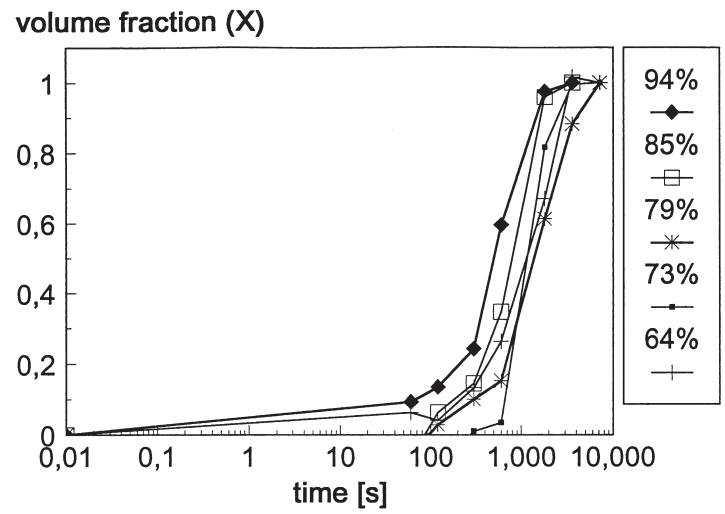

Fig. 9. Volume fraction of recrystallized grains measured by hardness indentations. 


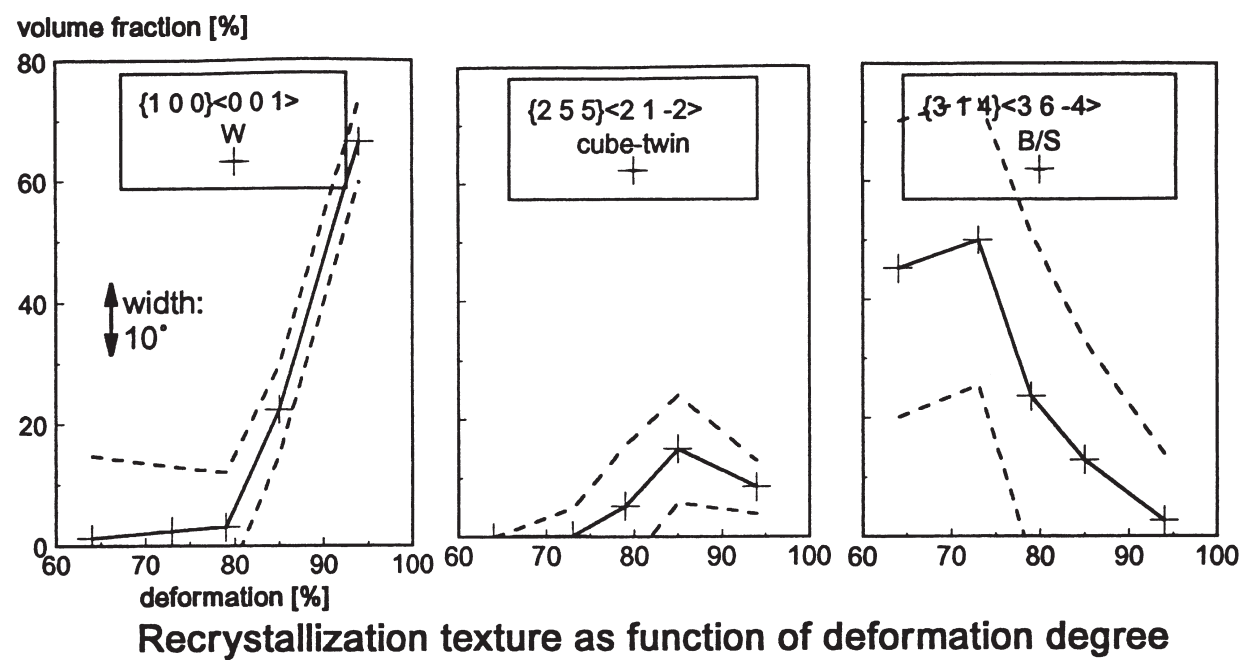

a)
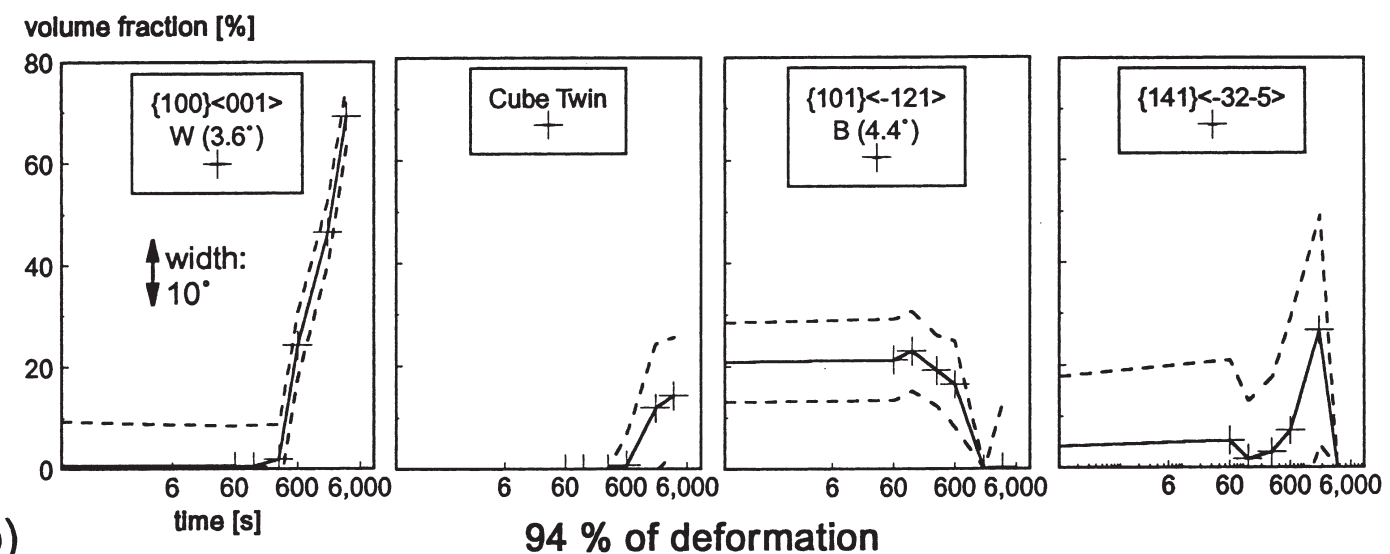

b)

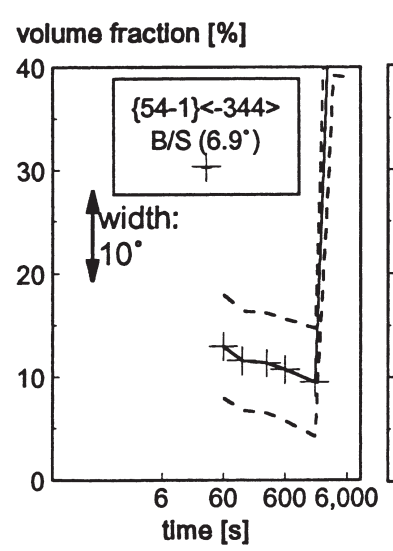

$94 \%$ of deformation

c)
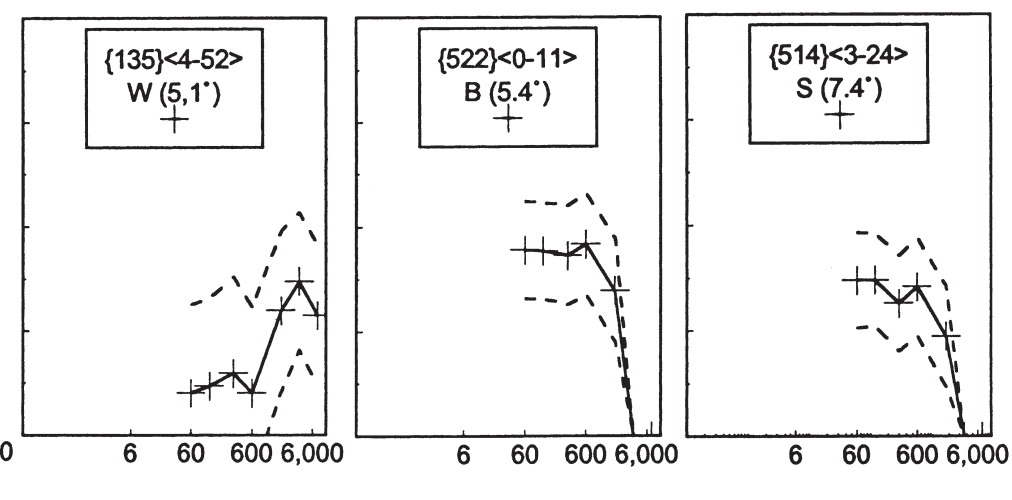

$79 \%$ of deformation

Recrystallization texture evolution as function of annealing time

Fig. 10. Development of the most important recrystallization texture components (a) as a function of the degree of cold rolling prior to complete recrystallization, (b) as a function of time for the $94 \%$ cold rolled material, and (c) as a function of time for the $79 \%$ cold rolled material. 


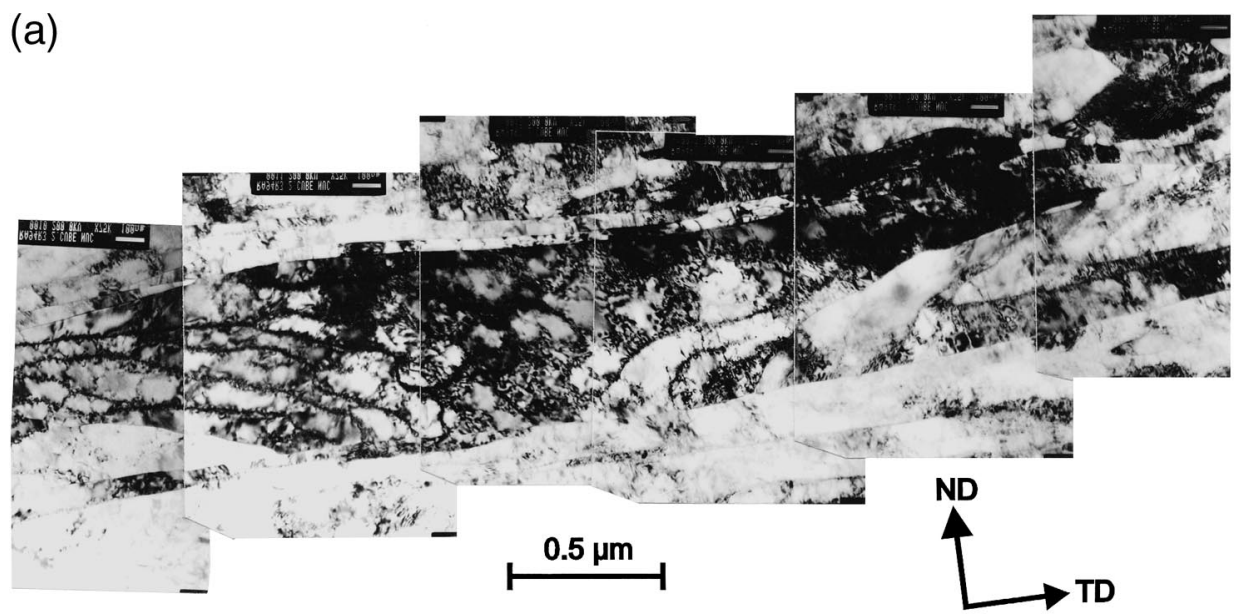

(b)
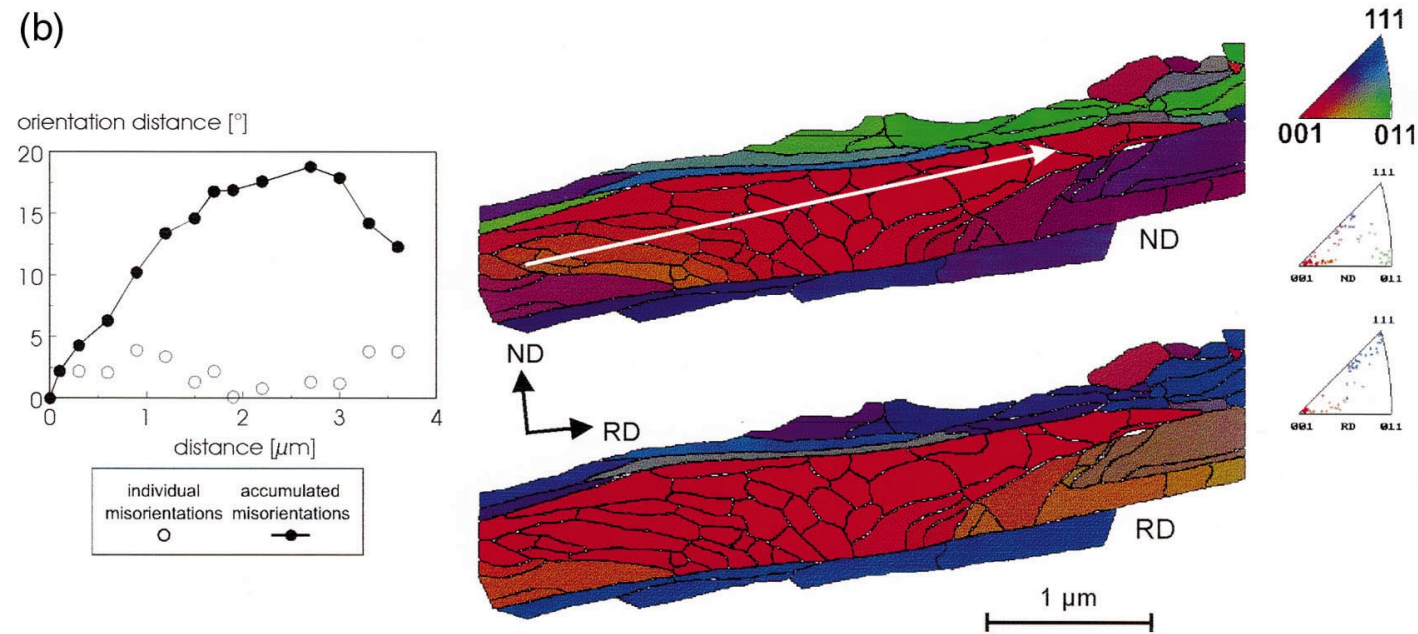

Fig. 11. (a) TEM micrograph and (b) orientation map from a cube band in the $94 \%$ deformed material measured on the ND-TD plane after $1 \mathrm{~min}$ of annealing. The graph on the left side indicates the misorientations measured along the white arrow in the map.

\begin{tabular}{|c|c|c|c|c|c|}
\hline Grain no. 1 & \multicolumn{2}{|l|}{ Grain no. 2} & \multicolumn{2}{|c|}{ Rotation axis $\langle u v w\rangle$} & Rotation angle $\omega\left(^{\circ}\right)$ \\
\hline \multicolumn{6}{|c|}{ Misorientations to neighbors outside the cube band } \\
\hline 1 & 81 & 0.424 & 0.599 & 0.679 & 56.882 \\
\hline 1 & 80 & 0.436 & 0.601 & 0.67 & 53.793 \\
\hline 1 & 79 & 0.363 & 0.596 & 0.716 & 57.357 \\
\hline 8 & 83 & 0.056 & 0.074 & 0.996 & 43.066 \\
\hline 10 & 83 & 0.02 & 0.197 & 0.98 & 42.383 \\
\hline 11 & 87 & 0.347 & 0.617 & 0.706 & 54.075 \\
\hline 12 & 88 & 0.323 & 0.649 & 0.689 & 60.298 \\
\hline 13 & 89 & 0.433 & 0.617 & 0.657 & 44.834 \\
\hline 13 & 90 & 0.446 & 0.632 & 0.634 & 45.814 \\
\hline 13 & 14 & 0.068 & 0.679 & 0.731 & 58.092 \\
\hline 13 & 23 & 0.393 & 0.434 & 0.81 & 29.621 \\
\hline \multicolumn{6}{|c|}{ Misorientations to neighbors inside the cube band } \\
\hline 1 & 8 & 0.043 & 0.376 & 0.925 & 1.515 \\
\hline 1 & 2 & 0.244 & 0.652 & 0.718 & 1.377 \\
\hline 1 & 16 & 0.114 & 0.568 & 0.815 & 2.258 \\
\hline 1 & 15 & 0.191 & 0.569 & 0.8 & 34.076 \\
\hline 1 & 40 & 0.069 & 0.13 & 0.989 & 4.331 \\
\hline 1 & 43 & 0.091 & 0.134 & 0.987 & 2.741 \\
\hline 1 & 42 & 0.007 & 0.04 & 0.999 & 4.494 \\
\hline
\end{tabular}


(a)
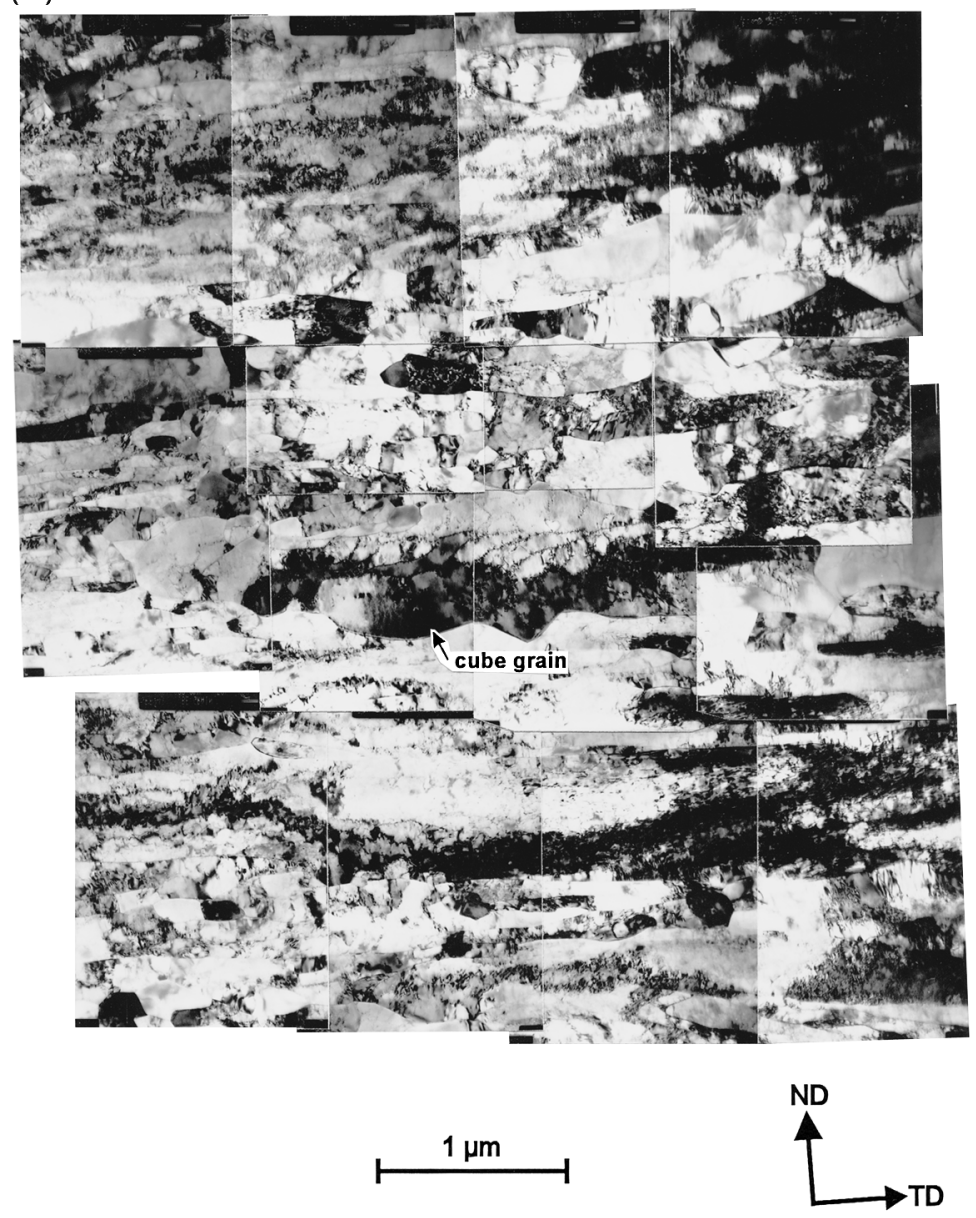

(b)

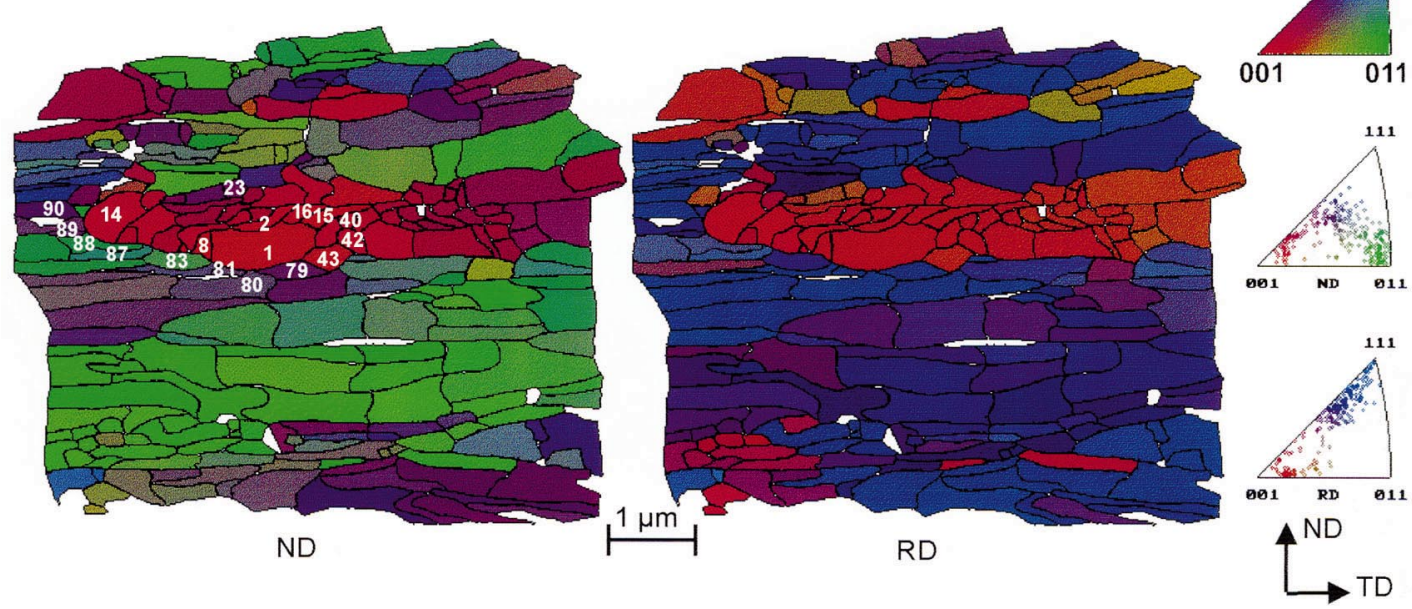

Fig. 12. (a) TEM micrograph and (b) orientation map of the $94 \%$ deformed material after 2 min of annealing (cube grains indicated in (a)): development of a cube nucleus inside a former cube band. The misorientations between the grain and its neighbors in the deformed matrix are given in Table 1. 


\section{DISCUSSION}

A detailed knowledge of the development and structure of deformation inhomogeneities is essential for the understanding of the nucleation process. It has been shown in the literature $[25,26]$ that a successful nucleation process requires the existence of (i) a sufficiently large orientation gradient to create new large angle grain boundaries, (ii) well recovered strain free volume elements and (iii) sufficiently high stored energy as a driving force for the process. The observed deformation heterogeneities will be discussed with special regard to their nucleation capabilities.

\subsection{The evolution of the cold rolling microstructure}

Three different types of deformation-induced heterogeneities have been observed, all of which are discussed in the current literature in relation to cube texture development. These are lamella bands (LB), cube bands (CB) and shear bands (SB).

4.1.1. Lamella bands (LB). In the highestly deformed samples those regions which show the main deformation texture components $\mathrm{C}$ and $\mathrm{S}$ are composed of LB which are formed by a subdivision of grains by dense dislocation walls (DDW). The DDW themselves are created by the concentration of slip on favorably oriented coplanar glide systems [27]. The deformation texture transition at about $75 \%$ (Fig. 1) characterized by the strong increase of $\mathrm{C}$ and $\mathrm{S}$ with increasing deformation can be ascribed to the increasing alignment of the LB with the rolling plane, as shown by Hughes and Hansen [28] for pure Ni. Since DDW are strong obstacles to dislocations and since they become close (200-50 nm between 79 and $94 \%$ deformation) the dislocation glide is more and more restricted to those glide systems which are aligned with the DDW. This in turn leads to more and more directed crystal rotations and to the strong increase of the volume fraction of the texture components $\mathrm{S}$ and C. Since S and C are stable end positions [29] the misorientations between lamella do not form any orientation gradient but are scattered around these positions. The lack of an orientation gradient (Figs. $6 \mathrm{~b}$ and d) and of any recovery (Fig. 6c) leads to the assumption that LB are inappropriate to recrystallization nucleation.

4.1.2. Cube bands (CB). Cube bands are the most interesting heterogeneities since the nucleation of cube grains is occurring in these bands. The cube bands observed here are all created by the deformation of cube grains which existed in the starting material. This is proved by the following.

1. The existence of cube grains in the hot rolled sheet. The cube volume fraction decreases continuously with the amount of reduction.

2. The size of the deformed cube grains which is in agreement with the size expected from the appropriate deformation of grains with about $10 \mu \mathrm{m}$ original grain size.
3. The continuous observation of cube grains in the microstructure of differently deformed samples. The cellular microstructure found in the $40 \%$ deformed samples is also observable in the $95 \%$ deformed material.

4. The existence of sharp high angle grain boundaries around the cube grains. If the cube grains had been formed inside a transition band the cube oriented regions would be embedded in a homogeneous gradient reaching to the matrix orientation.

The development of the highly recovered cell structure in the deformed cube grains may be explained by a mechanism based on the special deformation behavior of cube grains as proposed by Ridha and Hutchinson [14]. Together with this cell structure all cube grains start from about $40 \%$ of deformation to develop a typical orientation gradient. At low deformations only a few cells close to triple points participate at this orientation gradient, resulting in a cumulated misorientation of about $15^{\circ}$ at $64 \%$ deformation (Fig. 4). With increasing deformation the misorientations increase to about $25^{\circ}$ at $94 \%$ owing to a reduction in cell size and an increase in the number of participating cells (Fig. 6b). The formation of the gradient is due to the fact that the cube orientation lies in a strongly diverging region of the orientation flow field, as has been shown, for example, by the calculations of Klein and Bunge [30]. For the exact cube orientation the rotation rate is 0 . The larger the orientation distance of a given orientation to the cube orientation (in the vicinity of the cube orientation), the larger the rotation rate. A slight crystal rotation which has been "nucleated" at the grain boundary will thus "grow" into the cube oriented region, whereby the region which first began to rotate (close to the grain boundary) will eventually be rotated furthest away from the original cube orientation. A sketch of this situation is given in Fig. 13.

The CB are excellent candidates for the nucleation of cube grains because they show a high orientation gradient, a high misorientation across the band and well recovered cells.

4.1.3. Shear bands (SB). After high degrees of deformation (>85\%) SB develop which contain highly deformed cells with orientations completely different from those of the matrix orientation. However, neither cells of cube orientation nor any nucleation during recrystallization could be observed in the poorly developed SB of this study. Thus, in this investigation, very fine grained material SB did not play a role in recrystallization texture formation. 


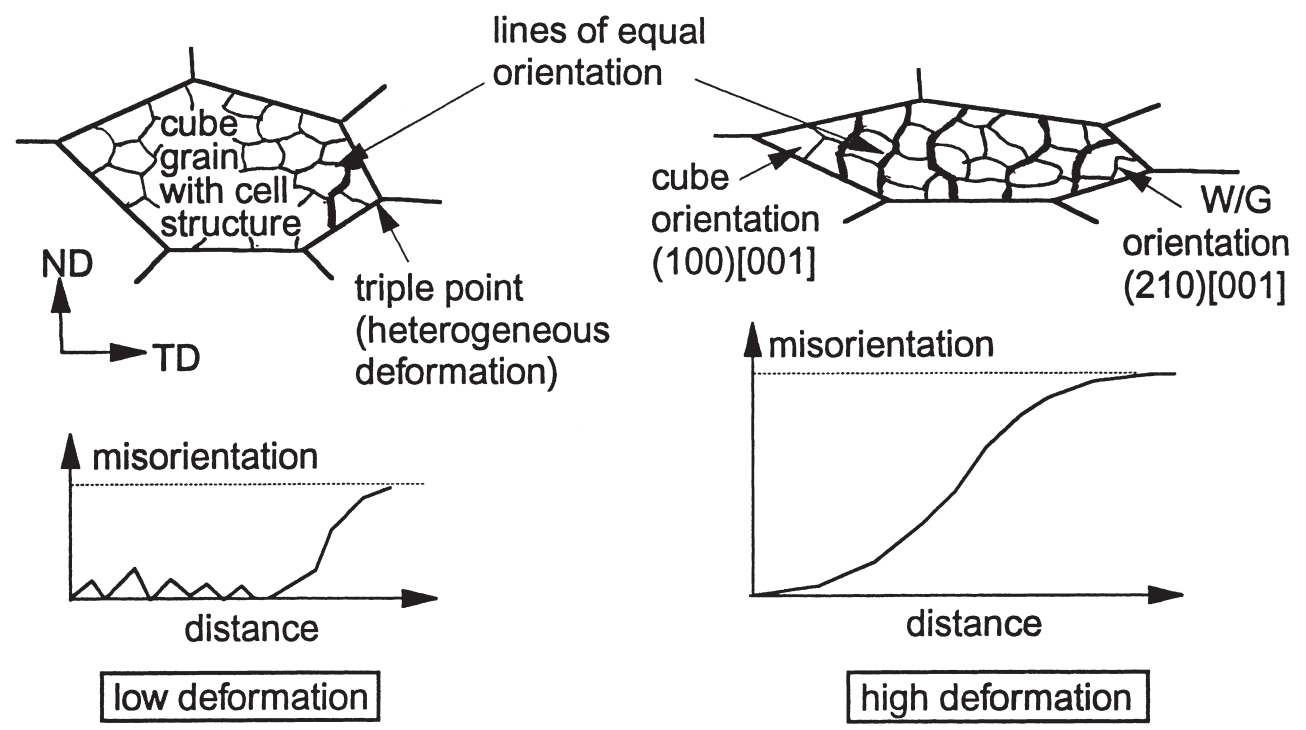

a)

b)

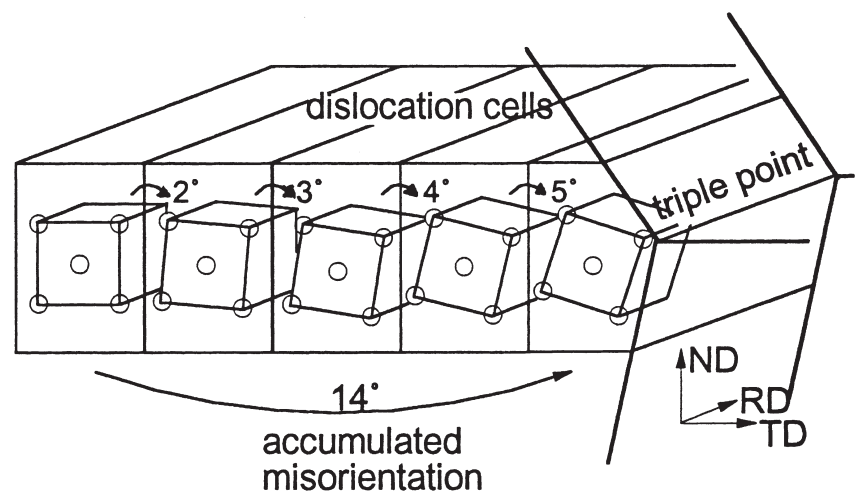

Fig. 13. Schematic drawing of the development of a cube band with its characteristic orientation gradient (a) and of the crystal lattice arrangement inside the gradient (b). 


\subsection{Recrystallization texture evolution}

A model for cube texture evolution must be based on the microstructural assumptions of the deformed structure and must take into account the following observations, made during the recrystallization experiments.

1. No cube texture develops for deformations smaller than $79 \%$ and only a few cube grains develop in the material c79 although cube oriented regions exist in the deformed structure for all degrees of deformation.

2. A pure cube texture develops after high deformations $(\geq 95 \%)$ and only cube nuclei are observed at the beginning of recrystallization.

3. Two kinetics are observed in material c79 (Fig. 10c): cube grains develop significantly earlier than non-cube grains. This observation is also confirmed by the kinetic measurements (Fig. 9). The samples which develop the cube texture recrystallize significantly earlier than those which develop another recrystallization texture. The recrystallization kinetics of the cube grains in c94 (Fig. 10b) is quite similar to that of the cube grains in c79.

4. The final cube recrystallization texture shows a characteristic spread around the rolling direction (Fig. 15).

5. The development of the cube texture in the recrystallized material starts just at the deformation stage at which the deformation texture starts to develop the typical "copper" cold rolling texture components $\mathrm{C}$ and $\mathrm{S}$. The evolution of $\mathrm{C}$ and $\mathrm{S}$ in the deformation texture and the cube component in the recrystallization texture seem to be parallel (compare Figs 1 and 10a).
4.2.1. The formation of cube nuclei. From point (1) and microstructural observations of the beginning of the recrystallization process it is clear that the nucleation process does not simply proceed by a bulging-out of pre-existing large angle grain boundaries at cube oriented sites. It would otherwise not be understandable why no cube texture develops in material $c<79$. The bulging process over a single cell is hindered because it would create a very sharp bulging radius which is energetically unfavorable. A possible nucleation process thus may proceed inside the cube band as proposed in the following.

A recrystallization nucleus, as it is understood here, is a dislocation-free crystal which may grow under a release of energy into the deformed matrix. Therefore, the nucleus must possess high angle grain boundaries with its neighbors (high mobility) and must exceed a critical size (energy release). According to the data presented in Ref. 9, a mobile grain boundary must exceed a misorientation angle of about $18-20^{\circ}$. The critical nucleus size is roughly given by the equilibrium of the release of deformation energy and the consummation of grain boundary energy when increasing the grain size. It is dependent on the stored energy, the type of the grain boundary and the misorientation across it. In the case discussed here the critical size for the development of cube nuclei in the $\mathrm{CB}$ can be estimated to about $1 \mu \mathrm{m}$, assuming that nucleation proceeds inside the cube band. $\dagger$ The deformed material shows maximum cell sizes of about $200 \mathrm{~nm}$ and it is thus clear that the critical nucleus size has to be reached by the slow process of subgrain growth or coalescence during annealing prior to recrystallization. The observations on the 1min annealed samples (widening of the cell boundaries and decrease of the diffraction pattern quality which can be interpreted as a rise of the dislocation density in the cell interior) give some evidence to the process of coalescence. However, the experimental observations are not sufficient to be sure of the actual process.

$\dagger$ The stored deformation energy is mainly located in the low angle grain boundaries (LAGB) of the CB. The inter-face energy of the LAGB $\gamma_{\mathrm{LAGB}}$ is calculated from the mis-orientation $\theta$ across the cell boundaries using the Read-Shockley formula [31]. For $\theta=4^{\circ}$ we find $\gamma_{\mathrm{LAGB}} \sim 0.317 \mathrm{~J} \mathrm{~m}^{-2}$. The surface of LAGB per volume $s_{\mathrm{V}}$ is calculated assuming tubeshaped cells with a radius $r_{\text {cell }}$ in the ND-TD plane $\left(r_{\text {cell }} \sim 50 \mathrm{~nm}\right)$. We find $s_{\mathrm{V}}=1 / r_{\text {cell. }}$. Thus, the stored energy per volume $\gamma_{\mathrm{V}}$ can be estimated to $\gamma_{\mathrm{V}}=\gamma_{\mathrm{LAGB}} / r_{\text {cell }}$. The equilibrium of consumed high angle grain boundary (HAGB) energy $\gamma_{\mathrm{HAGB}}$ and released volume energy during nucleus growth leads to the conditions for the critical nucleus size:

$$
r=3 \gamma_{\mathrm{HAGB}} / \gamma_{\mathrm{v}}
$$

Murr [32] gives a value of $\gamma_{\mathrm{HAGB}}=0.866 \mathrm{~J} \mathrm{~m}^{-2}$ for $\mathrm{Ni}$ and $0.855 \mathrm{~J} \mathrm{~m}^{-2}$ for stainless steel. With these values, a critical radius of $r_{\mathrm{c}} \sim 400 \mathrm{~nm}$ is calculated. 
Figure 12 shows a successfully growing nucleus. Some of the deformation cell boundaries are still visible. Figure $14 \mathrm{a}$ demonstrates the process schematically: initially, the misorientation between neighboring cells is small, which means the sub-grain growth process inside of the band is slow but possible in terms of energy and kinetics. A growth of well recovered cells at the band boundary into the surrounding deformation matrix, in contrast, is difficult because this would require a too small bulging radius of the large angle grain boundary. As the growth of sub-grains into the band proceeds, the misorientation between the growing sub-grain and its neighbors becomes larger. As soon as the sub-grain attains a sufficient misorientation and exceeds the critical grain size (Fig. 14b), the process of nucleation is finished and the nucleus continues its growth with a high growth rate under energy release. If a sub-grain reaches the band boundaries before exceeding the necessary misorientation, however, the nucleation process is stopped and the cube texture development inhibited.
In the proposed nucleation process the deformed matrix around a $\mathrm{CB}$ does not participate in the formation of the cube. A nucleation model which does not depend on the matrix orientation has also been proposed by Vatne et al. [11] for aluminum. In contrast, for copper the micro-oriented growth model has been proposed [7] in which the deformed matrix is considered necessary to form nuclei of sufficient size.

The nucleation process described in cube bands would be quite rapid compared with nucleation processes in other orientations because well recovered regions already exist in the deformed microstructure and a large angle grain boundary may be achieved quickly in the high orientation gradient. None of these properties are found in differently oriented regions. For these regions the slower process of strain induced grain boundary migration [33] has been proposed as a recrystallization mechanism [34]. The fact that the CB mechanism is significantly faster than other mechanisms is responsible for the split of the recrystallization kinetics of cube grains and non-cube grains observed in c79 and satisfies point (3) of Section 4.2. 


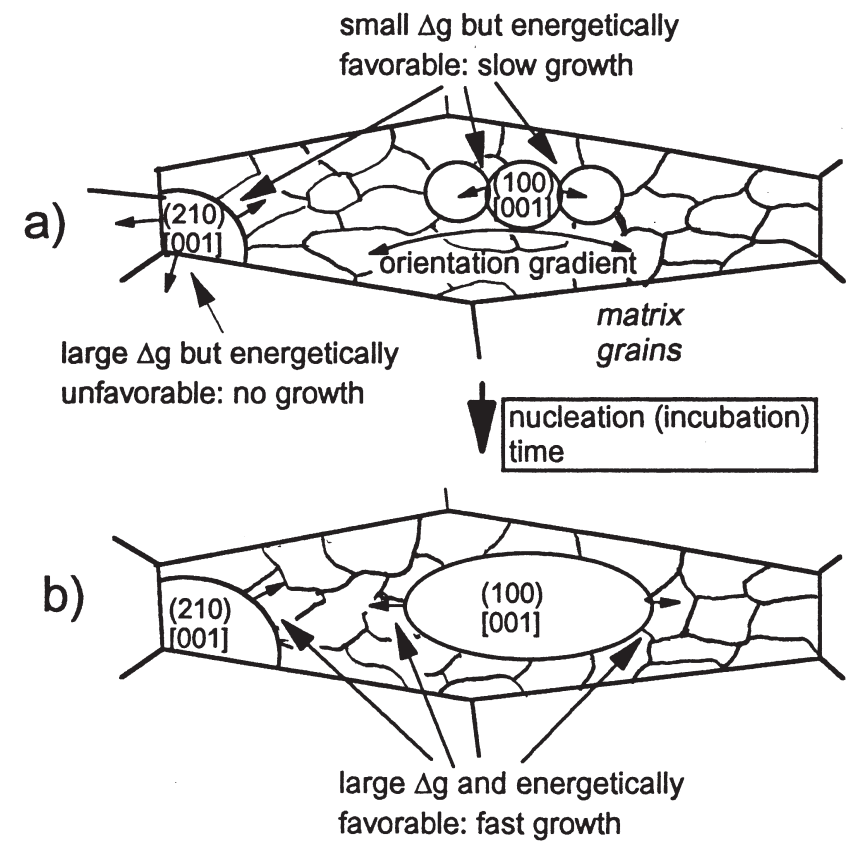

Fig. 14. Schematic representation of the development of a nucleus inside a cube band (a) after deformation and (b) after the incubation period.

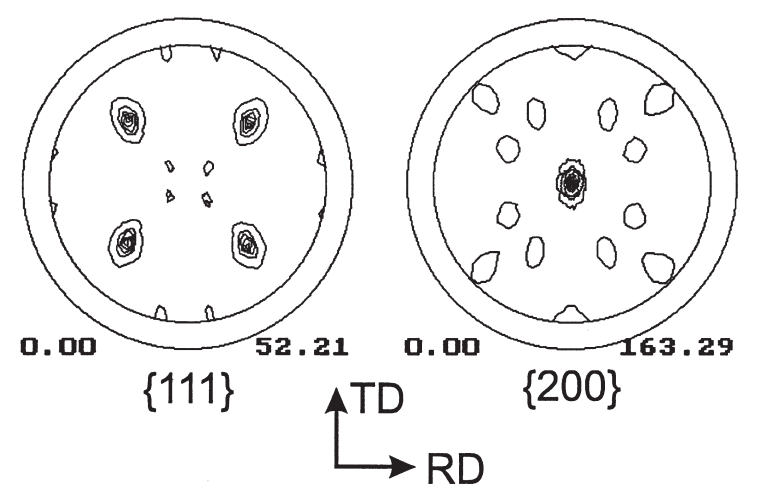

Fig. 15. $\{111\}$ and $\{200\}$ X-ray pole figures of the $94 \%$ deformed and completely recrystallized material, showing the orientation spread of the cube component around the rolling direction. Contour levels are given in steps of 10 between the maximum and the minimum values which are presented on the left and right sides of the pole figures, respectively. 
4.2.2. A model for cube texture formation. A model for cube texture evolution has to satisfy points (1)-(5) in Section 4.2. The first two points are of particular importance and we will start the discussion with the first, asking why no cube texture develops in material $c<79$ although cube oriented regions exist in the microstructure. In fact, the formation of a vital nucleus, as proposed here, requires the achievement of a large angle grain boundary (larger than $18^{\circ}$ ) inside the cube band and thus the existence of a sufficiently large misorientation $\Delta g$ across the CB in the deformed structure. However, for deformations smaller than $73 \%, \Delta g$ was in general smaller than $18^{\circ}$. It can be supposed that even in this material the $\mathrm{CB}$ nucleation process starts. However, since the misorientation across the bands is too small the process comes to an end when the matrix grain boundaries are reached without forming a vital nucleus. In the $94 \%$ deformed material, in contrast, all observed cube bands show misorientation of $\Delta g>25^{\circ}$ and nucleation in these bands is very probable. Further facts support the CB nucleation mechanism in c94:

In the microstructure of c94r120 only nuclei are detected whose orientations are comprised in those of the former CB. This is due to the fact that, in principle, nucleation may start at any position inside the $\mathrm{CB}$ as long as a sufficiently large misorientation can be achieved. As a direct result of this the final cube recrystallization texture shows exactly the same orientation spread as the cells in the CB. Figure 15 shows the X-ray pole figures of sample c94rCMP. The orientation spread around the rolling direction is evident. The cube orientation is the center of this spread since the exact cube oriented cells recover most rapidly. The observation point (4) in Section 4.2 is thus explained by the orientation distribution inside CB.

Moreover, we observed about the same density of $\mathrm{CB}$ as cube grains in the recrystallized material: on sample c94 about $7.1 \times 10^{9} \mathrm{CB}$ per $\mathrm{m}^{2}$ were measured. Taking into account a final grain size of $10 \mu \mathrm{m}$ the grain density per surface unit can be estimated as $1.3 \times 10^{10} \mathrm{~m}^{-2}$ which is within the tolerances of the measured value for the number of nucleation sites. This is a sign that virtually all $\mathrm{CB}$ in c94 lead to successful nucleation.

$\dagger$ According to the JMAK theory the recrystallized vol-ume fraction $X_{\mathrm{V}}$ as a function of recrystallization time $t$ can be expressed by $X_{\mathrm{V}}=1-\exp \left(-B t^{n}\right)$, where $B$ and $n$ are characteristic constants.
Although TEM observations on longer annealed samples were not carried out, it is clear from the observation of the behavior of non-cube grains (extensive polygonization of dislocations after $2 \mathrm{~min}$ of annealing) that nuclei of other orientations will be formed later as well. This assumption is further supported by the observation that the recrystallization textures for lower deformation degrees show the formation of non-cube orientations after at least twice the incubation time of cube grains. Some simple calculations, assuming a longer incubation period for non-cube grains, may give an estimation of the expected volume fraction of these grains after recrystallization. The recrystallized volume fraction of noncube oriented grains $X_{\text {non-w }}$ can be calculated, taking into account that a part $X_{\mathrm{W}}$ of the deformed volume has already been consumed by the growing cube (W) grains. Using the Johnson-Mehl-Avrami-Kolmogorov (JMAK) $\dagger$ approach, we find as a first much simplified solution (only valid for the beginning of recrystallization of non-cube grains):

$$
X_{\text {non-W }}(\tau, t)=\exp \left(-B(t-\tau)^{n}\right) X_{\mathrm{W}}
$$

where $\tau$ is the incubation time and $B$ and $n$ are the characteristic constants of the JMAK theory. We assume further that the non-cube grains grow at the same rate as the cube grains, i.e. $B_{\mathrm{W}}=B_{\text {non-w }}$ and $n_{W}=n_{\text {non-W. }}$. From a JMAK plot of the kinetics in Fig. 9 for the $94 \%$ deformed material, $B_{\mathrm{W}}=6.11 \times$ $10^{-4}$ and $n_{W}=1.1$. If we assume an incubation time of about $10 \mathrm{~min}$ (compared with 1-2 min for cube grains) we calculate a volume fraction of maximum $11 \%$ of grains of other orientations developing after 30 min of recrystallization (with $50 \%$ of cube grains). In fact, Fig. 10c shows the development of about $20 \%$ of the component $\{411\}<235\rangle$ after $30 \mathrm{~min}$ of recrystallization. As mentioned in Section 3.2.1, this value might be too high. Nevertheless, after complete recrystallization we find a pure cube texture. This means that the already grown non-cube grains are consumed by the cube grains. We thus have to assume grain growth proceeds at the same time as primary recrystallization. Grain growth is thermodynamically possible since the later nucleated non-cube grains are much smaller than the cube grains. Observation point (2), that exclusively cube texture is observed in c94, is thus due to the very effective and rapid $\mathrm{CB}$ nucleation mechanism combined with a grain growth process at the end of the recrystallization.

Finally, point (5) is discussed. The observation of the parallel development of the $\mathrm{C}$ and $\mathrm{S}$ components in the deformation texture and the cube texture in the recrystallization texture may lead to the assumption of an oriented growth mechanism for cube texture formation as has often been proposed in the literature $[8,9,35,36]$ or to a mechanism of micro-oriented growth for the nucleation [7]. The experiments and their interpretation here, however, support the theses of independence of both observations. Both texture developments are due to the development of deformation heterogeneities, namely of lamella bands in the case of the $\mathrm{C}$ and $\mathrm{S}$ deformation components and cube bands for the cube recrystallization component. Nevertheless, it remains unclear whether the parallel developments of $\mathrm{LB}$ and $\mathrm{CB}$ are related to each other. 


\section{CONCLUSIONS}

The mechanisms for the development of the sharp cube texture in $\mathrm{Fe}-36 \% \mathrm{Ni}$ during recrystallization after high cold rolling reductions have been studied. In contrast to $\mathrm{Al}$ and $\mathrm{Cu}$ which show a similar recrystallization texture evolution the alloy investigated here shows only very little recovery during cold rolling and the deformation structure can thus be studied in detail. The application of a special measurement system for the on-line crystal orientation determination in TEM allowed the measurement of local orientation distributions even in highly deformed materials. This gave new information about the mechanisms of cube recrystallization texture formation. The most important points are as follows.

1. The sharp cube recrystallization texture observed in highly deformed material develops because cube nuclei develop significantly quicker than nuclei of other orientations.

2. The high nucleation rate (not growth rate) is due to special properties of cube bands in the deformed matrix. Cube bands are subdivided into dislocation cells of approximately $200 \mathrm{~nm}$ diameter which show (a) a relatively high degree of recovery and (b) a characteristic orientation gradient. During the incubation time of recrystallization, nuclei develop inside these cells by cell growth or cell coalescence. The growth of cells in the orientation gradient leads to the formation of a large angle grain boundary and thus to a vital nucleus. The surrounding matrix of cube grains does not seem to play a role in nucleus formation.

3. The misorientation across the orientation gradient in the cube bands increases with increasing deformation. For low degrees of deformation the misorientation is too small to allow the formation of vital nuclei. Consequently no cube texture is formed.

4. The cube oriented regions which lead to cube nucleation are formed by the deformation of originally cube or near-cube oriented grains in the starting material.

5. The characteristic orientation gradient in cube oriented bands is ascribed to the very quickly changing crystal rotation field for orientations close to the cube orientation under rolling deformation. In contrast, in regions with orientations close to the stable end orientations $\mathrm{S}$ and $\mathrm{C}$ no orientation gradient is formed. Instead, the orientation of these sub-grains are scattered around the stable end orientations due to the rather weak changes in the orientation flow field around these orientations. As a consequence lamella bands which are observed in $\mathrm{S}$ and $\mathrm{C}$ oriented crystals do not form any vital nuclei.
6. The strong development of the $\mathrm{S}$ and $\mathrm{C}$ deformation texture components in the deformed material after $80 \%$ of deformation is not the origin of the development of the cube component in the recrystallized material. It is instead the parallel ripening of deformation heterogeneities, i.e. of cube bands for the cube texture and lamella bands for the deformation texture, which is responsible for the observed parallelism of the two texture formations.

Although the global texture evolution during deformation and recrystallization of $\mathrm{Al}, \mathrm{Cu}$ and $\mathrm{Fe}-36 \% \mathrm{Ni}$ are quite similar it cannot be concluded that the micro-mechanisms in these materials are the same. Quite different nucleation mechanisms have been proposed for $\mathrm{Cu}$ ("micro-oriented growth" [7]) and for Al ("size-advantage" [23]) although the latter might coincide with the mechanism proposed here after some annealing has been carried out. Further research might be able to reveal whether the proposed mechanism is only valid for $\mathrm{Fe}-36 \% \mathrm{Ni}$ or whether it has a more general validity.

Acknowledgements-The work presented here was made possible by a fellowship for S. Zaefferer granted to T. Baudin by the Académie des Sciences Française which is gratefully acknowledged. We also gratefully acknowledge Imphy S.A. for supply of the materials and financial support of S.Z. for a large period of his work. We especially thank F. Duffaut, P. L. Reydet and G. Couderchon of Imphy S.A. for the many helpful discussions. 


\section{REFERENCES}

1. Doherty, R. D. et al., Mater. Sci. Eng., 1997, A238, 219.

2. Humphreys, F. J. and Hatherly, M., Recrystallization and Related Phenomena. Elsevier Science, 1995, p. 85.

3. $\mathrm{Hu}, \mathrm{H}$., in Proceedings of the Seventh Ris International Symposium on Metallurgy and Material Science. 1986, p. 75.

4. Hutchinson, W. B. and Nes, E., in Seventh Risø International Symposium on Metallurgy and Material Science. 1986, p. 107.

5. Doherty, R. D., Kashyap, K. and Panchanadeeswaran, S., Acta metall. mater., 1993, 41, 3029.

6. Hjelen, J., Ørsund, R. and Nes, E., Acta metall. mater., 1991, 39, 1377.

7. Duggan, B. J. et al., Acta metall. mater., 1993, 41, 1921.

8. Juul Jensen, D., Acta metall. mater., 1995, 43, 4117.

9. Doherty, R. D., Chen, L. and Samajdar, I., Mater. Sci. Eng., 1998, A257, 18.

10. Weiland, H. and Hirsch, J. R., Textures Microstr., 1991, 14-18, 647.

11. Vatne, H. E., Furu, T. and Nes, E., Mater. Sci. Tech., 1996, 12, 201.

12. Dillamore, I. L. and Katoh, H., Metal Sci., 1974, 8, 73.

13. Kamijo, T. et al., Acta metall. mater., 1992, 40, 693.

14. Ridha, A. A. and Hutchinson, W. B., Acta metall., 1982, 30, 1929.

15. Kamijo, T., Kataoka, S. and Inagaki, H., Acta metall. mater., 1993, 41, 1713

16. Beaudouin, A. J., Mecking, H. and Kocks, U., Phil. Mag. A, 1996, 73, 1503.

17. Ray, R. K. and Lücke, K., in Proc. ICOTOM 7, Noordwijkerhood. 1984, p. 287.

18. Zaefferer, S., PhD Thesis, TU Clausthal, Papierflieger, Clausthal, 1995.

19. Zaefferer, S., J. Appl. Cryst., 2000, 33, 10.

20. Helming, K. et al., Z. Metallkd., 1994, 85, 545.

21. Amblard, J. et al., J. Micosc. Spectrosc. Electron., 1981, 6, 311 .

22. Gerth, D. and Schwarzer, R. A., Textures Microstruct., 1993, 21, 177.

23. Hirsch, J. and Lücke, K., Acta metall., 1988, 36, 2863.

24. Daaland, O. and Nes, E., Acta mater., 1996, 44, 1389.

25. Diallamore, I. L. et al., Proc. R. Soc. London, 1972, A329, 405.

26. Doherty, R. D. et al., in Proc. ICOTOM-8. Warrendale, PA, 1988.

27. Hirsch, J., Lücke, K. and Hatherly, M., Acta metall., 1988, 36, 2905.

28. Hughes, D. A. and Hansen, N., Met. Trans. A, 1993, 24A, 2021.

29. Chin, G. Y., in The Inhomogeneity of Plastic Deformation. Amercian Society for Metals, Ohio, 1973, p. 83.

30. Klein, H. and Bunge, H. J., in Advances and Applications of Quantitative Texture Analysis, ed. H. J. Bunge. DGM, Oberursel, 1989, p. 209.

31. Read, W. T. and Shockley, W., Phys. Rev., 1950, 78, 275.

32. Murr, L. E., Interfacial Phenomena in Metals and Alloys. Addison-Wesley Publishing Company, 1975, p. 131.

33. Bellier, S. P. and Doherty, R. D., Acta Metall., 1977, 25, 521 .

34. Engler, O., Vatne, H. E. and Nes, E., Mater. Sci. Eng., 1996, A205, 187.

35. Barret, C. S., Trans. AIME, 1940, 137, 128.

36. Beck, P. A., Acta metall., 1953, 1, 230. 